\title{
RNA Sequencing Reveals Diverse Functions of Amniotic Fluid Neutrophils and Monocytes/ Macrophages in Intra-Amniotic Infection
}

\author{
Nardhy Gomez-Lopez ${ }^{a, b, c}$ Roberto Romero a, d, e, f, g, h Aneesha Varrey ${ }^{a, b}$

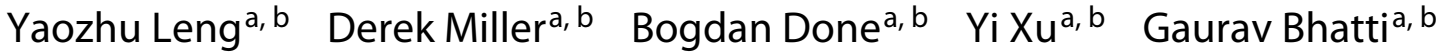 \\ Kenichiro Motomura ${ }^{a}, b \quad$ Meyer Gershater ${ }^{a, b}$ Roger Pique-Regi ${ }^{a, b, f}$
}

Adi L. Tarcaa, b, i

\begin{abstract}
aPerinatology Research Branch, Division of Obstetrics and Maternal-Fetal Medicine, Division of Intramural Research, Eunice Kennedy Shriver National Institute of Child Health and Human Development, National Institutes of Health, US Department of Health and Human Services (NICHD/NIH/DHHS), Bethesda, MD and Detroit, MI, USA; 'D Department of Obstetrics and Gynecology, Wayne State University School of Medicine, Detroit, MI, USA; 'Department of Biochemistry, Microbiology and Immunology, Wayne State University School of Medicine, Detroit, MI, USA; dDepartment of Obstetrics and Gynecology, University of Michigan, Ann Arbor, MI, USA; 'Department of Epidemiology and Biostatistics, Michigan State University, East Lansing, MI, USA; ${ }^{f}$ Center for Molecular Medicine and Genetics, Wayne State University, Detroit, MI, USA; ${ }^{\circ}$ Detroit Medical Center, Detroit, MI, USA; hepartment of Obstetrics and Gynecology, Florida International University, Miami, FL, USA; 'Department of Computer Science, Wayne State University College of Engineering, Detroit, MI, USA
\end{abstract}

\section{Keywords}

Chorioamnionitis - Fetal inflammatory response ·

Funisitis · Innate immunity · Microbial invasion of the amniotic cavity · Pregnancy · Preterm · Transcriptome

\begin{abstract}
Intra-amniotic infection, the invasion of microbes into the amniotic cavity resulting in inflammation, is a clinical condition that can lead to adverse pregnancy outcomes for the mother and fetus as well as severe long-term neonatal morbidities. Despite much research focused on the consequences of intra-amniotic infection, there remains little knowledge about the innate immune cells that respond to invading microbes. We performed RNA-seq of sorted amniotic fluid neutrophils and monocytes/macrophages from women with in-
\end{abstract}

karger@karger.com www.karger.com/jin

Karger $\stackrel{\text { ' }}{5}$

GOPEN ACCESS
(C) 2020 The Author(s)

Published by S. Karger AG, Basel

This article is licensed under the Creative Commons AttributionNonCommercial-NoDerivatives 4.0 International License (CC BYNC-ND) (http://www.karger.com/Services/OpenAccessLicense). Usage and distribution for commercial purposes as well as any distribution of modified material requires written permission. tra-amniotic infection to determine the transcriptomic differences between these innate immune cells. Further, we sought to identify specific transcriptomic pathways that were significantly altered by the maternal or fetal origin of amniotic fluid neutrophils and monocytes/macrophages, the presence of a severe fetal inflammatory response, and pregnancy outcome (i.e., preterm or term delivery). We show that significant transcriptomic differences exist between amniotic fluid neutrophils and monocytes/macrophages from women with intra-amniotic infection, indicating the distinct roles these cells play. The transcriptome of amniotic fluid immune cells varies based on their maternal or fetal origin, and the significant transcriptomic differences between fetal and maternal monocytes/macrophages imply that those of fetal origin exhibit impaired functions. Notably, transcriptomic changes in amniotic fluid monocytes/macrophages suggest that these 
immune cells collaborate with neutrophils in the trafficking of fetal leukocytes throughout the umbilical cord (i.e., funisitis). Finally, amniotic fluid neutrophils and monocytes/macrophages from preterm deliveries display enhanced transcriptional activity compared to those from term deliveries, highlighting the protective role of these cells during this vulnerable period. Collectively, these findings demonstrate the underlying complexity of local innate immune responses in women with intra-amniotic infection and provide new insights into the functions of neutrophils and monocytes/macrophages in the amniotic cavity.

(C) 2020 The Author(s)

Published by S. Karger AG, Basel

\section{Introduction}

Intra-amniotic infection is a clinical condition resulting from the invasion of microbes into the amniotic cavity [1-9], namely Ureaplasma urealyticum, Mycoplasma hominis, Streptococcus agalactiae, Gardnerella vaginalis, and Escherichia coli, among others [10-21]. Microbial invasion leads to a local inflammatory response characterized by increased concentrations of cytokines [22-30], antimicrobial peptides [31-38], and lipids [39-52] in the amniotic fluid. In some cases, this local infection can result in maternal systemic inflammation (i.e., clinical chorioamnionitis) [10, 53-59]. Consequently, intra-amniotic infection is associated with maternal morbidity $[57,60$, 61] as well as neonatal morbidity and mortality [62-71]. Therefore, investigation focused on the immunobiology of intra-amniotic infection is highly relevant for mothers and children.

The cellular immune repertoire in the amniotic cavity of women with intra-amniotic infection is mainly composed of innate immune cells (e.g., neutrophils and monocytes/macrophages) [72-81]. Yet, other less-abundant immune cell subsets such as T cells, B cells, NK cells, and innate lymphoid cells are also present in the amniotic cavity of women with intra-amniotic infection [78, 79]. Due to their abundance, we recently proposed that amniotic fluid neutrophils and monocytes/macrophages, which can originate from the fetus [82-85] and/or the mother [84-86], serve as the frontline of host innate immune responses against microbes invading this compartment $[77,78]$. However, it is unclear whether their maternal or fetal origin determines the function of such innate immune cells.

Neutrophils exert a variety of host defense functions to capture and destroy invading microbes [87-91]. In the amniotic cavity, such mechanisms include phagocytosis
[92], the release of antimicrobial products [31-38, 93], and the formation of neutrophil extracellular traps (NETs) [94]. Conversely, the traditional view has been that amniotic fluid monocytes/macrophages primarily release pro-inflammatory cytokines [77, 80]; yet their functions have been overlooked as neutrophils represent the majority of innate immune cells in this compartment. Therefore, we hypothesized that apparent functional dissimilarities exist between neutrophils and monocytes/ macrophages in the amniotic cavity, which are driven by their transcriptomic profiles.

Importantly, intra-amniotic infection can lead to a fetal inflammatory response [95-102], which manifests as acute histopathological lesions of the umbilical cord and chorionic plate [103], conditions known as funisitis and chorionic vasculitis, respectively [103-105]. This fetal inflammatory response is characterized by elevated concentrations of inflammatory mediators in the umbilical cord blood [97, 98, 106-110]. However, whether the fetal inflammatory response could be associated with changes in the transcriptomes of neutrophils and monocytes/macrophages present in the amniotic cavity during intra-amniotic infection has been unexplored.

The aim of this study was to conduct transcriptomic analysis of neutrophils and monocytes/macrophages from the amniotic cavity of women with intra-amniotic infection by using RNA-seq to characterize the molecular pathways and biological processes associated with differential expression between these innate immune cell types. Further, we assessed the effects on transcriptomic pathways based on changes in the fetal or maternal origin of amniotic fluid neutrophils and monocytes/macrophages, the presence of a severe fetal inflammatory response, and pregnancy outcome (preterm or term delivery).

\section{Methods}

Human Subjects and Clinical Specimens

Human amniotic fluid samples were obtained at the Perinatology Research Branch, an intramural program of the Eunice Kennedy Shriver National Institute of Child Health and Human Development, National Institutes of Health, U.S. Department of Health and Human Services, Wayne State University (Detroit, MI, USA), and the Detroit Medical Center (Detroit, MI, USA). The collection and use of human materials for research purposes were approved by the Institutional Review Boards of the National Institute of Child Health and Human Development and Wayne State University. All participating women provided written informed consent prior to sample collection. The patient inclusion criteria were as follows: (1) amniotic fluid samples without blood contamination and (2) amniotic fluid samples with a large number of viable leukocytes $\left(>1 \times 10^{5}\right.$ cells $\left./ \mathrm{mL}\right)$ sufficient to perform fluorescence-ac-
Gomez-Lopez et al. 
tivated cell sorting (FACS) of amniotic fluid neutrophils and monocytes/macrophages. Amniotic fluid leukocyte counts and viability were determined using an automatic cell counter (Cellometer Auto 2000; Nexcelom Bioscience, Lawrence, MA, USA) and the ViaStain AOPI Staining Solution (Nexcelom Bioscience). The clinical and demographic characteristics of the patients are shown in Table 1.

\section{Clinical Definitions}

Gestational age was established based on the last menstrual period and ultrasound. Term delivery was defined as birth $\geq 37$ weeks of gestation, whereas preterm delivery was defined as birth $<37$ weeks of gestation. The presence of viable bacteria in the amniotic cavity was evaluated by amniotic fluid culture as previously described, which included culture for genital mycoplasmas $[12,13]$. Intra-amniotic inflammation was defined as an amniotic fluid interleukin (IL)- 6 concentration $\geq 2.6 \mathrm{ng} / \mathrm{mL}[111,112]$. Intra-amniotic infection was defined as the presence of cultivable bacteria together with intra-amniotic inflammation $[17,18,113,114]$.

\section{Amniotic Fluid Sample Collection}

Amniotic fluid was retrieved by transabdominal amniocentesis to detect intra-amniotic infection. Amniotic fluid samples were transported to the clinical laboratory in a capped sterile syringe and FACS was performed immediately. Additionally, an aliquot of amniotic fluid was transported to the clinical laboratory for culture of aerobic/anaerobic bacteria and genital mycoplasmas. The clini$\mathrm{cal}$ and research tests also included the determination of an amniotic fluid white blood cell (WBC) count [72, 73], Gram stain examination [115], glucose concentration [116], and IL-6 concentration [111]. Bacterial live/dead staining was performed as previously described to immediately visualize the presence of microbes in amniotic fluid $[94,117]$.

\section{Determination of Interleukin-6 in Amniotic Fluid}

Interleukin- 6 concentrations in amniotic fluid were evaluated using a sensitive and specific enzyme immunoassay from $R \& D$ Systems (Minneapolis, MN, USA) as previously established [111]. The IL- 6 concentrations were determined by interpolation from the standard curves. The inter- and intra-assay coefficients of variation for IL-6 were 8.7 and 4.6\%, respectively. The detection limit of the IL- 6 assay was $0.09 \mathrm{pg} / \mathrm{mL}$.

\section{FACS of Amniotic Fluid Neutrophils and Monocytes/ Macrophages}

To remove epithelial cells, each amniotic fluid sample was passed through a sterile $15-\mu \mathrm{m}$ filter (Cat\# 43-50015-03; pluriSelect Life Science, Leipzig, Germany) and centrifuged at $200 \mathrm{~g}$ for $5 \mathrm{~min}$ at room temperature. The resulting amniotic fluid pellet was washed with $1 \times \mathrm{PBS}$, resuspended at $1 \times 10^{6}$ cells in $100 \mu \mathrm{L}$ of BD FACS stain buffer containing 20\% human FcR blocking reagent, and incubated for $10 \mathrm{~min}$ at $4^{\circ} \mathrm{C}$. Next, amniotic fluid cells were incubated with the following fluorochrome-conjugated anti-human antibodies (BD Biosciences, San Jose, CA, USA) for $30 \mathrm{~min}$ at $4^{\circ} \mathrm{C}$ in the dark: CD14-APC-Cy7 (clone M $\phi$ P9, Cat $\#$ 557831; BD Biosciences) and CD15-FITC (clone W6D3, Cat\# 562370; BD Biosciences). After washing with $1 \times$ PBS, the cells were resuspended in pre-sort buffer (Cat\# 563503; BD Biosciences) at a concentration of $5 \times 10^{6}$ cells $/ \mathrm{mL}$. Amniotic fluid neutrophils $\left(\mathrm{CD} 15^{+} \mathrm{CD} 14^{-}\right.$ cells) and monocytes/macrophages $\left(\mathrm{CD} 14^{+} \mathrm{CD} 15^{-}\right.$cells) were pu-

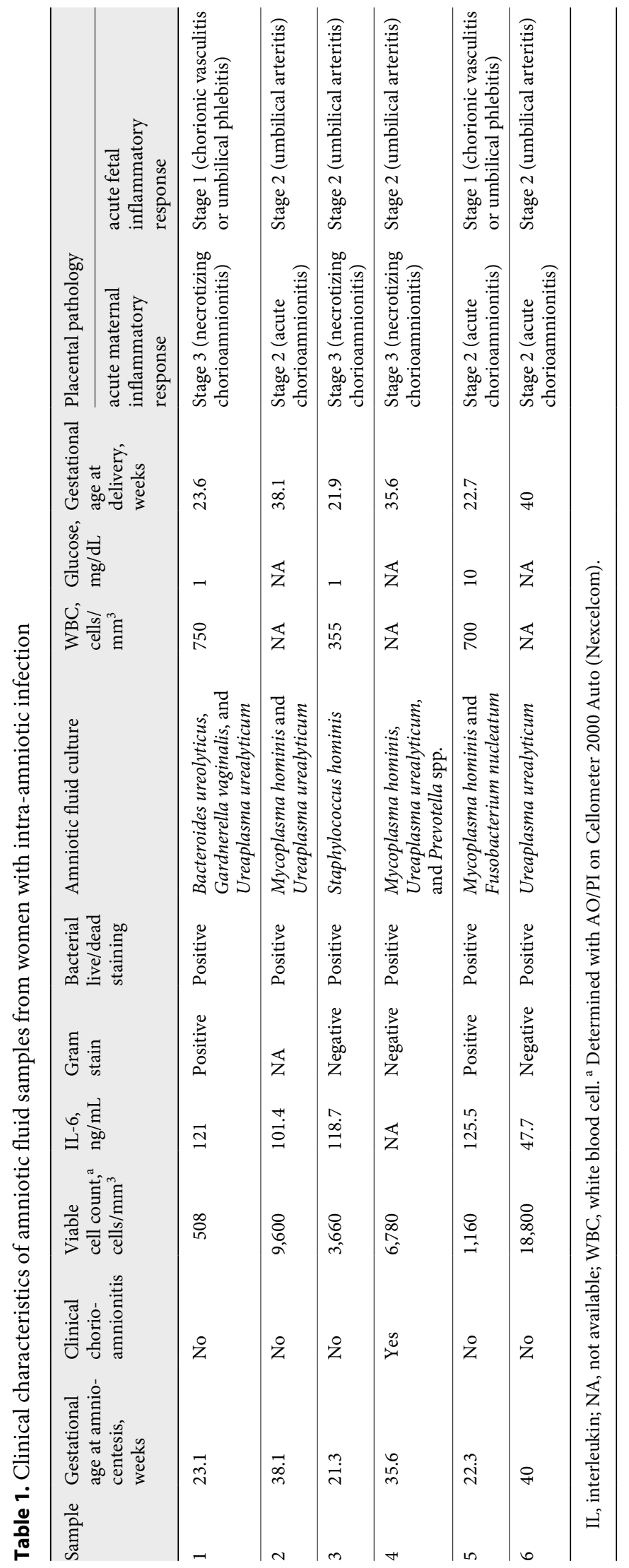

Innate Immun 2021;13:63-82

DOI: $10.1159 / 000509718$
RNA-seq of Amniotic Fluid Innate Immune Cells in Intra-Amniotic Infection 


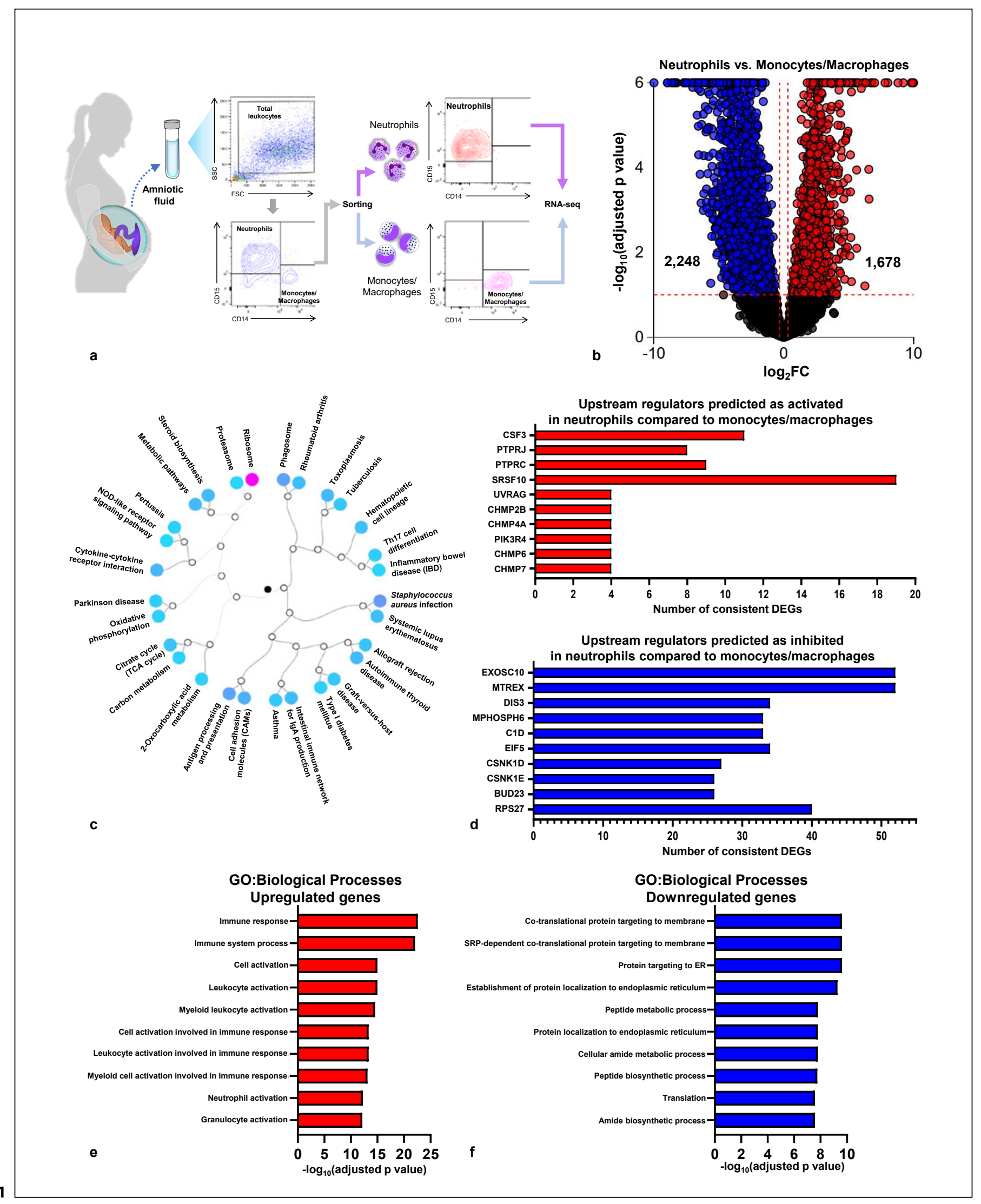

(For legend see next page.) 
rified using a BD FACSAria cell sorter (BD Biosciences) and BD FACSDiva 6.0 software (BD Biosciences). The purified neutrophils and monocytes/macrophages were then resuspended in RLT buffer (Qiagen, Germantown, MD, USA) and stored at $-80^{\circ} \mathrm{C}$ until RNA isolation.

\section{RNA Isolation}

RNA was isolated from lysed amniotic fluid cells using the Qiagen Micro RNeasy kit (Qiagen), following the manufacturer's instructions. The purity, concentration, and integrity of the RNA samples were assessed using the NanoDrop 1000 spectrophotometer (Thermo Scientific, Wilmington, DE, USA) and the Bioanalyzer 2100 (Agilent Technologies, Wilmington, DE, USA). The low-input RNA-seq library was prepared by the Beijing Genomics Institute (BGI; Wuhan, China) using the Smart-Seq2 kit (Illumina, San Diego, CA, USA). Paired-end sequence reads (120 million total reads per sample) of 150-bp length were generated using the NovaSeq sequencer (Illumina), and raw data were provided by BGI.

\section{RNA-seq Data Analysis}

Transcript abundance from RNA-seq reads was quantified with Salmon [118] and used to test for differential expression with a negative binomial distribution model implemented in the DESeq2 [119] package from Bioconductor [120]. Gene expression changes were assessed through 7 between-group comparisons: (1) total neutrophils - total monocytes/macrophages, (2) fetal maternal neutrophils, (3) fetal - maternal monocytes/macrophages, (4) severe - mild fetal inflammatory response neutrophils, (5) severe - mild fetal inflammatory response monocytes/macrophages, (6) preterm - term neutrophils, and (7) preterm - term monocytes/macrophages. Genes with a minimum fold change of 1.25 -fold and an adjusted $p$ value of $<0.1$ were considered differentially expressed.

The differentially expressed genes (DEGs) for each betweengroup comparison were used as input in iPathwayGuide (ADVAITA Bioinformatics, Ann Arbor, MI, USA) [121-123] to determine the significantly impacted pathways. iPathwayGuide pathway annotations were derived from the Kyoto Encyclopedia of Genes and Genomes (KEGG) database, release 90.0+/05-29 [124, 125]. Significantly perturbed pathways (false discovery rate adjusted $p$ values $<0.1$ ) were presented hierarchically in a dendrogram based on the overlap in associated DEGs. Volcano plots were used to display the evidence of differential expression for each comparison. The top 10 most significantly enriched Gene Ontology (GO) biological processes in strictly upregulated or downregulated genes are also shown.

Fig. 1. Transcriptomic differences between amniotic fluid neutrophils and monocytes/macrophages from women with intra-amniotic infection. a Experimental design showing the FACS of amniotic fluid neutrophils $(n=6)$ and monocytes/macrophages $(n=6)$ for RNA-seq. b Volcano plot showing the DEGs between amniotic fluid neutrophils and monocytes/macrophages. c Hierarchical dendrogram showing KEGG pathway impact analysis between amniotic fluid neutrophils and monocytes/macrophages. Pink circle indicates the most significantly affected pathway, and the lightest blue circles indicate the least significantly affected path-
Further, to gain insight and to visualize gene dysregulation in the comparisons described above, we used the stringApp (version 1.5.0) [126] in Cytoscape (version 3.7.2) [127] to test the overrepresentation of GO biological processes [128] in the upregulated and downregulated genes separately. A false discovery rate-adjusted $p$ value $<0.05$ determined statistical significance. We constructed networks ofhigh-confidence protein-protein interactions (STRING confidence score $>0.7$ ) and very high-confidence protein-protein interactions (STRING confidence score $>0.9$ ) for each set of DEGs. For each network, we retained the most inter-connected subnetwork or subnetworks of proteins for visualization and highlighted biological processes enriched among these gene sets.

\section{DNA Fingerprinting}

The origin of amniotic fluid neutrophils and monocytes/macrophages was determined using DNA fingerprinting, as previously reported $[84,85]$. Briefly, genomic DNA was isolated from FACS-purified amniotic fluid neutrophils and monocytes/macrophages, and fetal or maternal genomic DNA was isolated from frozen samples of either umbilical cord or maternal blood (buffy coat), respectively, as previously described $[84,85]$. DNA samples (amniotic fluid neutrophils and monocytes/macrophages, umbilical cord blood, and maternal blood) were sent for DNA fingerprinting to Genetica DNA Laboratories (https://www.celllineauthentication.com, Laboratory Corporation of America/LabCorp, Burlington, NC, USA) for analysis of the 13 core CODIS STR loci plus PENTA E, PENTA D, and the gender-determining locus, amelogenin. The origin of amniotic fluid neutrophils and monocytes/ macrophages was designated as either predominantly maternal or predominantly fetal.

\section{Placental Histopathologic Examination and Umbilical Cord} Imaging

Histopathologic examination of the placenta was performed by perinatal pathologists blinded to clinical diagnoses and obstetrical outcomes according to standardized Perinatology Research Branch protocols [104]. Acute inflammatory lesions of the placenta (maternal inflammatory response and fetal inflammatory response) were diagnosed according to established criteria, including staging and grading [104]. Fetal inflammatory responses were histologically evaluated by the presence and severity of acute lesions (i.e., neutrophil invasion) in the umbilical cord (funisitis) or chorionic plate (chorionic vasculitis) $[103,104]$. Severity is reported as stages, where stage 1 indicates umbilical phlebitis and/or chorionic vasculitis (mild inflammation), stage 2 indicates umbilical arteritis (severe inflammation), and stage 3 indicates necrotizing funisitis (total inflammation and necrosis in the umbilical cord) [104]. For visual-

ways. d Predicted activated and inhibited upstream regulators for DEGs in amniotic fluid neutrophils compared to monocytes/ macrophages. e, f GO analysis using genes significantly upregulated (e) or genes significantly downregulated (f) in amniotic fluid neutrophils compared to monocytes/macrophages. The top 10 significantly affected biological processes from each set of DEGs are shown. FC, fold change; FACS, fluorescence-activated cell sorting; DEGs, differentially expressed genes; GO, Gene Ontology; KEGG, Kyoto Encyclopedia of Genes and Genomes. 


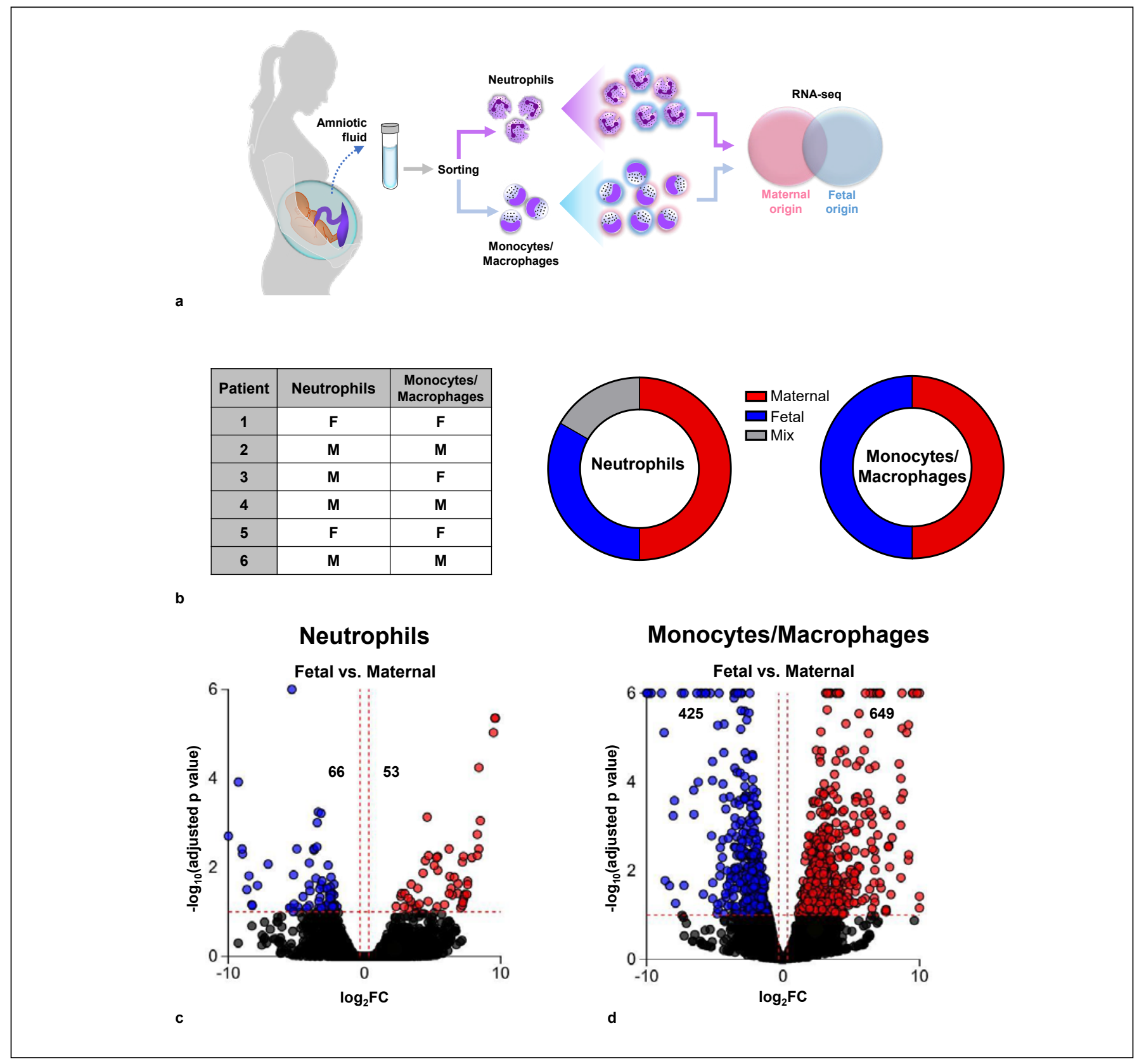

Fig. 2. Transcriptomic differences between amniotic fluid neutrophils and monocytes/macrophages of predominantly fetal or maternal origin. a Experimental design demonstrating the transcriptomic comparison between amniotic fluid neutrophils or monocytes/macrophages of predominantly fetal and maternal origin. b Table and pie charts representing the maternal (neutrophils, $n=$ 4; monocytes/macrophages, $n=3$ ) or fetal (neutrophils, $n=2$;

ization of umbilical cord inflammation, 5 - $\mu$ m-thick sections of formalin-fixed, paraffin-embedded umbilical cord specimens were cut and mounted on SuperFrost ${ }^{\mathrm{TM}}$ Plus microscope slides (Erie Scientific LLC, Portsmouth, NH, USA). Following deparaffinization, the monocytes/macrophages $n=3$ ) origins of amniotic fluid neutrophils and monocytes/macrophages determined using DNA fingerprinting. c, d Volcano plots showing the differentially expressed genes among amniotic fluid neutrophils (c) and monocytes/macrophages (d) of fetal origin compared to those of maternal origin. $\mathrm{M}$, predominantly maternal origin; $\mathrm{F}$, predominantly fetal origin; FC, fold change.

slides were rehydrated and stained with hematoxylin and eosin. Images of stained umbilical cord sections were taken using the Vectra Polaris Automated Quantitative Pathology Imaging System (Akoya Biosciences, Marlborough, MA, USA).
68

I Innate Immun 2021;13:63-82 DOI: $10.1159 / 000509718$
Gomez-Lopez et al. 


\section{Results}

Transcriptomic Differences between Neutrophils and Monocytes/Macrophages in the Amniotic Cavity of Women with Intra-Amniotic Infection

First, to obtain a broad view of the transcriptomic differences between amniotic fluid neutrophils and monocytes/macrophages, we sorted $\mathrm{CD} 15^{+} \mathrm{CD} 14^{-}$cells and $\mathrm{CD} 14^{+} \mathrm{CD} 15^{-}$cells from women with intra-amniotic infection (Table 1) and performed RNA-seq in these cells (Fig. 1a). We identified a total of 3,926 DEGs between amniotic fluid neutrophils and monocytes/macrophages, of which 2,248 genes were downregulated (blue dots) and 1,678 were upregulated (red dots) as displayed in a volcano plot (Fig. 1b). Next, the DEGs were used as input to determine significantly affected gene pathways obtained from the KEGG database (see Methods for details). Twenty-nine significantly affected pathways were identified, which included multiple immune-related pathways such as "Staphylococcus aureus infection," "phagosome," "antigen processing and presentation," "cell adhesion molecules," and "cytokine-cytokine receptor interactions," among others (Fig. 1c). We then analyzed the upstream regulators of the DEGs that were predicted as activated or inhibited in amniotic fluid neutrophils compared to monocytes/macrophages: several regulators were identified (Fig. 1d). Increased gene expression in amniotic fluid neutrophils compared to monocytes/macrophages was associated with biological processes such as "immune response," "leukocyte activation," "neutrophil activation," and "granulocyte activation" (Fig. 1e). Among downregulated genes in amniotic fluid neutrophils, enriched biological processes included "co-translational protein targeting to membrane," "SRP-dependent co-translational protein targeting to membrane," "protein targeting to ER," and "establishment of protein localization to endoplasmic reticulum" (Fig. 1f). These findings show that cell type-specific transcriptomic differences exist between amniotic fluid neutrophils and monocytes/macrophages in women with intra-amniotic infection, indicating that these innate immune cells display distinct host immune functions against microbes invading the amniotic cavity.

\section{The Transcriptome of Amniotic Fluid Neutrophils} and Monocytes/Macrophages Differs Based on Their

Maternal or Fetal Origin

Previous reports have shown that innate immune cells of fetal or maternal origin, or occasionally a mixture of both, are found in the amniotic cavity during intra-amniotic infection $[84,85]$. Thus, we performed RNA-seq to compare the transcriptomes of amniotic fluid neutrophils and monocytes/macrophages between those of primarily fetal origin and those of primarily maternal origin (Fig. 2a). The maternal or fetal origin of amniotic fluid neutrophils and monocytes/macrophages was previously determined using DNA fingerprinting $[84,85]$. The samples included herein were designated as either predominantly of maternal or fetal origin. Sorted amniotic fluid neutrophils were of predominantly maternal origin in $67 \%(4 / 6)$ of patients and were primarily derived from the fetus in 33\% (2/6) of patients (Fig. 2b). Sorted amniotic fluid monocytes/macrophages were evenly split in origin, with $50 \%(3 / 6)$ being derived from the mother and 50\% $(3 / 6)$ from the fetus (Fig. 2b). One sample of predominantly maternal neutrophils also contained a fraction of fetal neutrophils, represented as "Mix" (grey area) in the pie chart shown in Figure 2b. A total of 119 genes were differentially expressed in predominantly fetal neutrophils compared to predominantly maternal neutrophils, of which 66 were downregulated and 53 were upregulated, as shown in a volcano plot (Fig. 2c). In contrast, the transcriptome of amniotic fluid monocytes/macrophages appeared to be more influenced by their origin, as 1,074 genes were differentially expressed in predominantly fetal monocytes/macrophages compared to predominantly maternal monocytes/macrophages (Fig. 2d). Among these DEGs, 425 were downregulated and 649 were upregulated in predominantly fetal monocytes/macrophages compared to those of predominant maternal origin (Fig. 2d). Given the low number of DEGs determined in neutrophils of predominantly fetal or maternal origin, subsequent analyses revealed no enrichment of specific pathways or GO terms in these cells. Thus, we further explored the transcriptomic differences observed in the monocytes/macrophages.

KEGG pathway analysis revealed 8 pathways that were significantly perturbed in amniotic fluid monocytes/ macrophages of predominantly fetal or maternal origin: "S. aureus infection," "systemic lupus erythematosus," "pertussis," "cholesterol metabolism," "Chagas disease (American trypanosomiasis)," "bladder cancer," "legionellosis," and "complement and coagulation cascades," suggesting that the transcriptomic differences between these cells are primarily related to immune response to infection (Fig. 3a). Upstream regulator prediction analysis in amniotic fluid monocytes/macrophages identified the aryl hydrocarbon receptor (AHR) as activated in predominantly fetal monocytes/macrophages compared to those of predominantly maternal origin (Fig. 3b). Strikingly, multiple inflammatory mediators such as tumor 


\section{Monocytes/Macrophages}
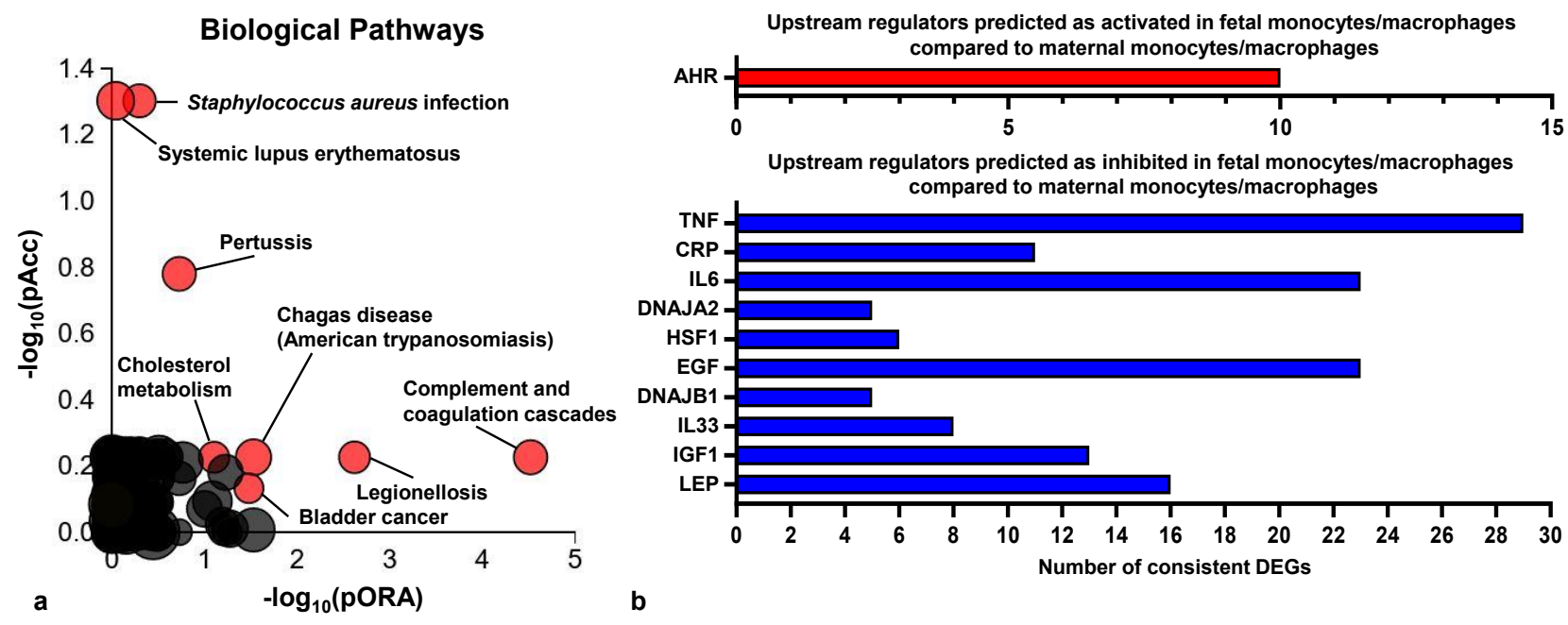

b
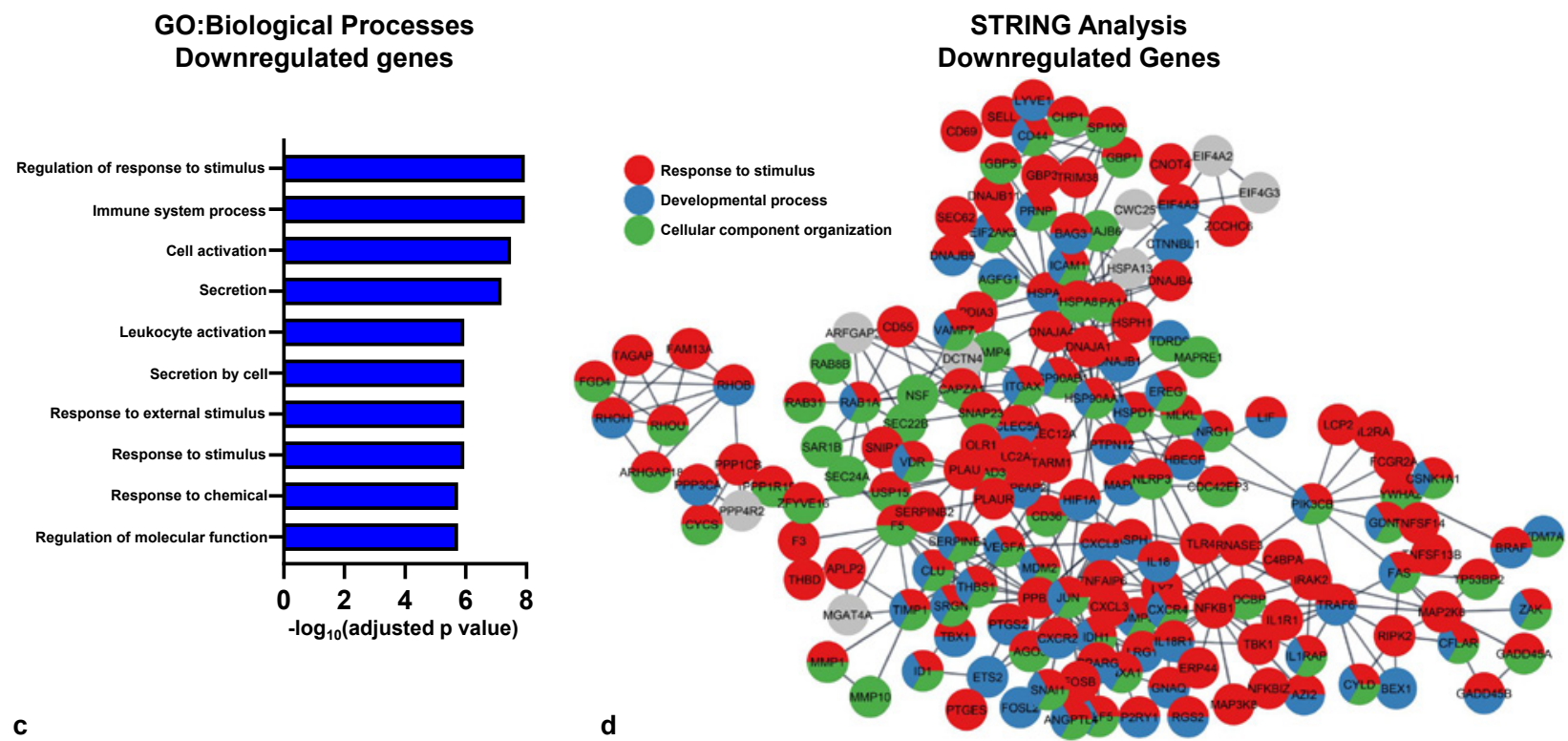

c

Fig. 3. Transcriptomic differences between amniotic fluid monocytes/macrophages of predominantly fetal or maternal origin. a pORA and total pAcc showing KEGG pathway impact analysis between predominantly fetal $(n=3)$ and maternal $(n=3)$ amniotic fluid monocytes/macrophages. Significantly impacted pathways are shown in red. b Predicted activated and inhibited upstream regulators of DEGs in amniotic fluid monocytes/macrophages of predominantly fetal origin compared to those of predominantly maternal origin. c GO analysis using genes significantly downregulated in amniotic fluid monocytes/macrophages of predominantly fetal origin compared to those of predominantly maternal origin. The top 10 significantly enriched biological processes are shown. d STRING analysis showing a subset of genes downregulated in amniotic fluid monocytes/macrophages of predominantly fetal origin compared to those of predominantly maternal origin, represented as nodes in the network. The edges between nodes represent high-confidence protein-protein interactions for the corresponding genes. Red, "response to stimulus" network; blue, "developmental process" network; green, "cellular component organization" network; pORA, plot based on gene overrepresentation; pAcc, pathway accumulation; DEGs, differentially expressed genes; GO, Gene Ontology; KEGG, Kyoto Encyclopedia of Genes and Genomes. 


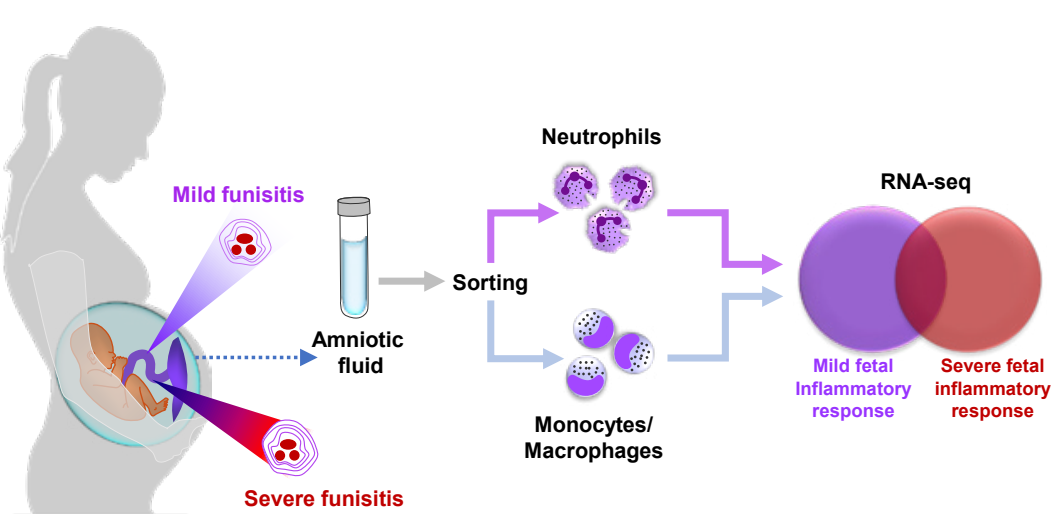

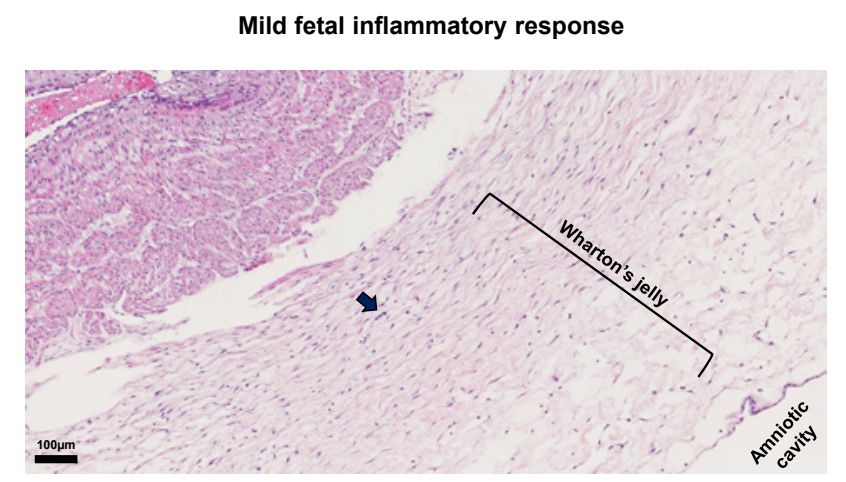

b

\section{Neutrophils}

Severe vs. Mild Fetal Inflammatory Response

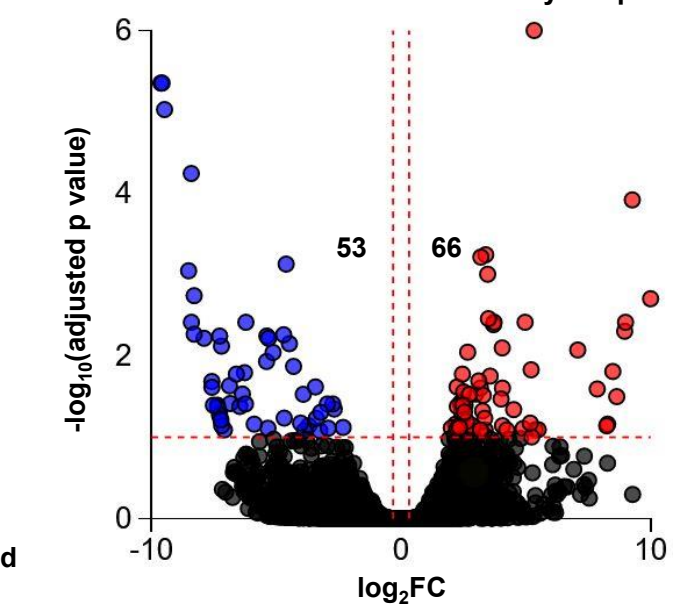

Severe fetal inflammatory response

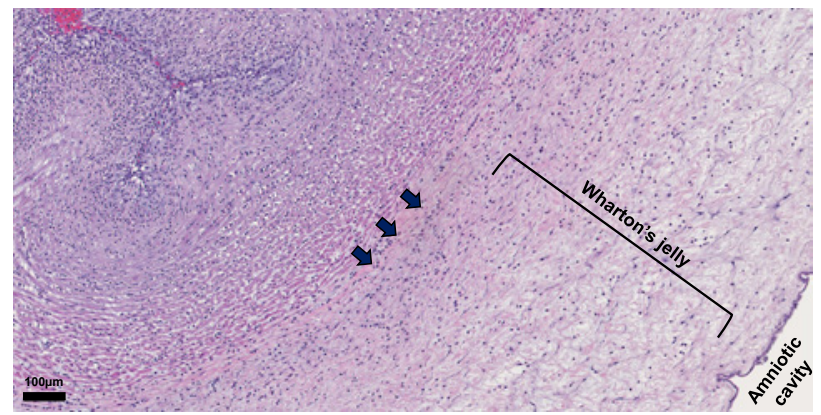

C

\section{Monocytes/Macrophages}

Severe vs. Mild Fetal Inflammatory Response

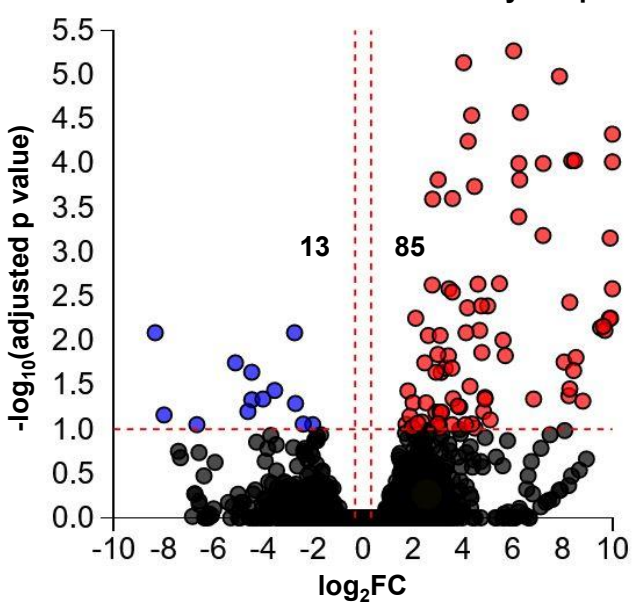

Fig. 4. Transcriptomic differences between amniotic fluid neutrophils or monocytes/macrophages from cases of severe and mild fetal inflammatory response. a Experimental design demonstrating the transcriptomic comparison of amniotic fluid neutrophils or monocytes/macrophages between cases of mild $(n=2)$ and severe $(n=4)$ fetal inflammatory response. b, c Representative images of umbilical cord hematoxylin and eosin (H\&E) staining showing mild (b) and severe (c) fetal inflammatory response indi- cated by leukocyte infiltration in the Wharton's jelly localized near the umbilical artery (arrows). Magnification $=\times 10$, scale bar $=100$ $\mu \mathrm{m}$. d, e Volcano plots showing the differentially expressed genes among amniotic fluid neutrophils (d) and monocytes/macrophages (e) from cases of severe fetal inflammatory response compared to those from cases of mild fetal inflammatory response. FC, fold change. 


\section{Monocytes/Macrophages}

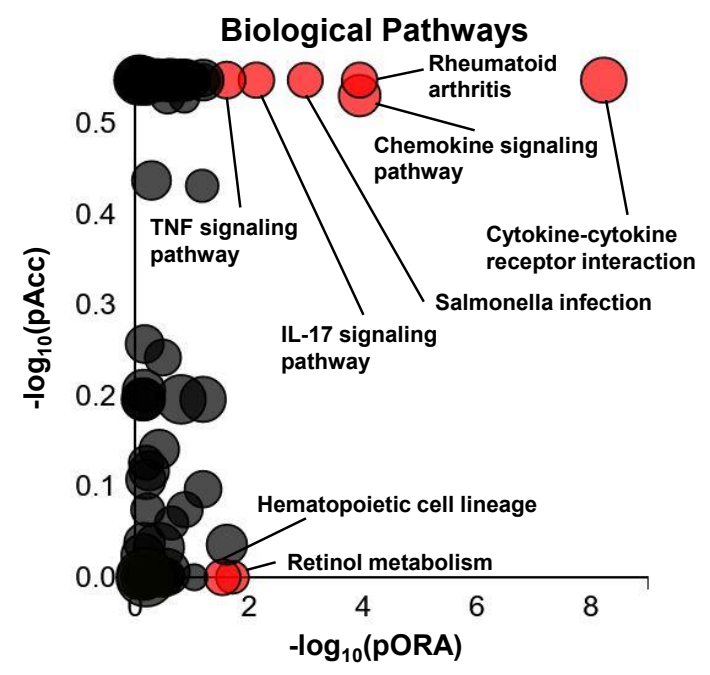

a

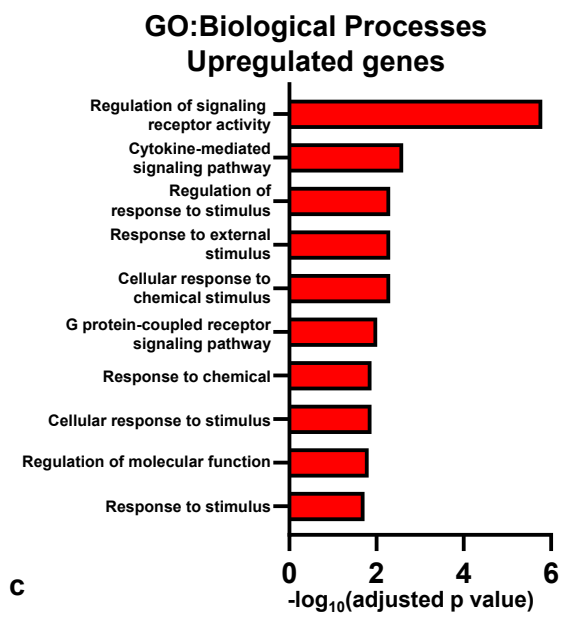

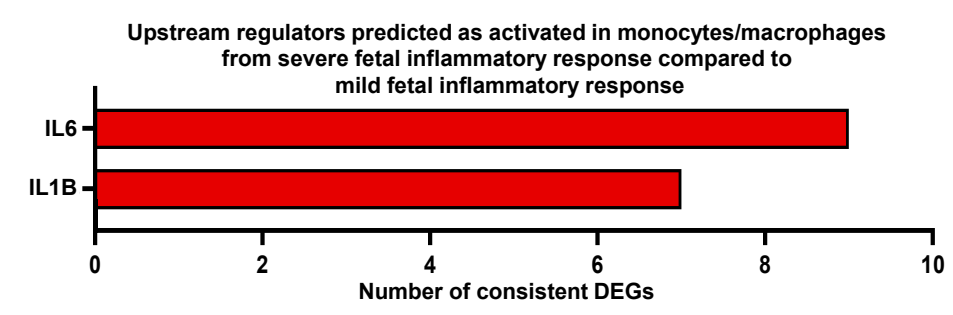

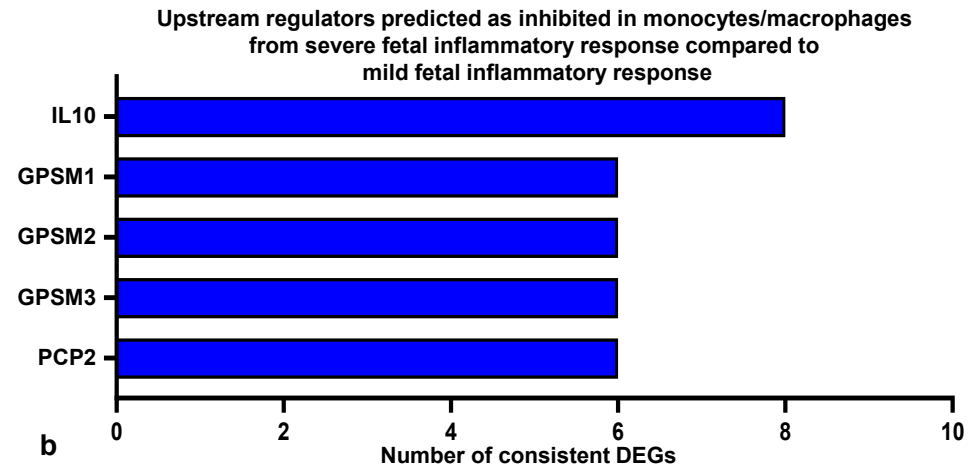

STRING Analysis

Upregulated Genes

Cytokine-mediated signaling pathway

Regulation of cell population proliferation

Extracellular matrix assembly

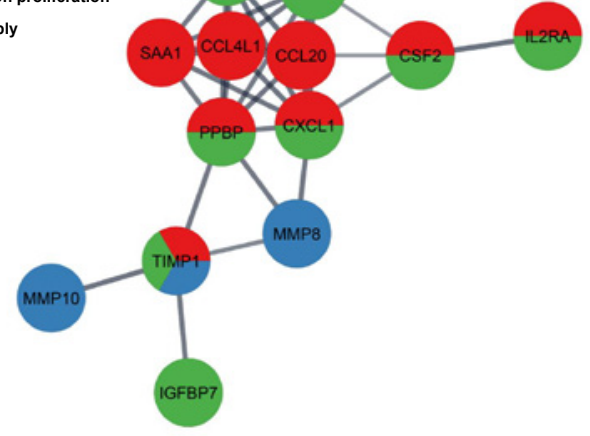

Fig. 5. Transcriptomic differences between amniotic fluid monocytes/macrophages from cases of severe and mild fetal inflammatory response. a pORA and total pAcc showing KEGG pathway impact analysis between amniotic fluid monocytes/macrophages from cases of severe fetal inflammatory response $(n=4)$ compared to those from cases of mild fetal inflammatory response $(n=2)$. Significantly impacted pathways are shown in red. b Predicted activated and inhibited upstream regulators of DEGs in amniotic fluid monocytes/macrophages from cases of severe fetal inflammatory response compared to those from cases of mild fetal inflammatory response. c GO analysis using genes significantly upregulated in amniotic fluid monocytes/macrophages from cases of severe fetal inflammatory response compared to those from cases of mild fetal inflammatory response. The top 10 significantly enriched biological processes are shown. d STRING analysis showing a subset of genes upregulated in amniotic fluid monocytes/macrophages from cases of severe fetal inflammatory response compared to those from cases of mild fetal inflammatory response, represented as nodes in the network. The edges between nodes represent high-confidence protein-protein interactions for the corresponding genes. Red, "cytokine-mediated signaling pathway" network; blue, "regulation of cell population proliferation" network; and green, "extracellular matrix assembly" network; pORA, plot based on gene overrepresentation; pAcc, pathway accumulation; DEGs, differentially expressed genes; GO, Gene Ontology; KEGG, Kyoto Encyclopedia of Genes and Genomes. 
necrosis factor (TNF), C-reactive protein (CRP), IL-6, and IL-33 were predicted as inhibited in predominantly fetal monocytes/macrophages compared to those of predominantly maternal origin, suggesting lower activation of transcriptomic pathways related to inflammation (Fig. 3b). GO analysis was performed using significantly upregulated or downregulated genes in predominantly fetal monocytes/macrophages compared to predominantly maternal monocytes/macrophages to determine enriched biological processes. Among the genes downregulated in predominantly fetal monocytes/macrophages compared to predominantly maternal monocytes/macrophages, enriched GO terms included "regulation of response to stimulus," "immune system process," "cell activation," and "secretion," as well as multiple terms related to response to external stimuli (Fig. 3c). Three of these biological processes are shown on the highly connected network obtained with STRING software (Fig. 3d). STRING enrichment analysis identified "response to stimulus," "developmental process," and "cellular component organization" as enriched in genes downregulated in monocytes/macrophages of predominantly fetal origin compared to those of predominantly maternal origin (Fig. 3d). No biological processes were significantly enriched among genes upregulated in predominantly fetal monocytes/macrophages compared to predominantly maternal monocytes/macrophages.

Taken together, these findings indicate that the origin of immune cells in the amniotic cavity influences their transcriptome. Specifically, the significant transcriptomic differences between fetal and maternal monocytes/ macrophages suggest that fetal monocytes/macrophages exhibit impaired functions.

\section{Transcriptomic Changes in Amniotic Fluid}

Neutrophils and Monocytes/Macrophages Based on the Severity of the Fetal Inflammatory Response

Intra-amniotic infection is associated with a fetal inflammatory response [95-102], which manifests histologically as lesions of the umbilical cord and chorionic plate $[103,104]$. Thus, we next determined the differential gene expression in amniotic fluid neutrophils and monocytes/macrophages from cases of a severe (stage 2) fetal inflammatory response $(n=4)$ compared to those from cases of a mild (stage 1) fetal inflammatory response $(n=2)$ (Table 1; Fig. 4a). Representative hematoxylin and eosin staining illustrates the infiltration of granulocytes into the tissue surrounding the umbilical artery in the severe fetal inflammatory response, in contrast with the minor infiltration of these cells observed in the mild fetal inflammatory response (Fig. 4b-c). Amniotic fluid neutrophils displayed differential expression of 119 genes between cases of severe or mild fetal inflammatory response, with 53 DEGs downregulated and 66 DEGs upregulated (Fig. 4d). Amniotic fluid monocytes/macrophages showed a total of 98 DEGs, with the majority ( 85 genes) being upregulated and only 13 downregulated (Fig. 4e). Despite the similar numbers of DEGs observed in amniotic fluid neutrophils and monocytes/macrophages from cases of severe or mild fetal inflammatory response, subsequent pathway analysis of DEGs revealed significant enrichment of pathways and GO terms for monocytes/macrophages alone. Thus, we focused on the transcriptomic differences occurring in amniotic fluid monocytes/macrophages in the context of the fetal inflammatory response.

The severity of the fetal inflammatory response was associated with significant enrichment of 8 KEGG pathways in amniotic fluid monocytes/macrophages: "TNF signaling pathway," "IL-17 signaling pathway," "Salmonella infection," "chemokine signaling pathway," "rheumatoid arthritis," "cytokine-cytokine receptor interaction," "hematopoietic cell lineage," and "retinol metabolism" (Fig. 5a). These pathways suggest that the DEGs affected by the fetal inflammatory response are largely related to cytokine signaling and propagation of inflammation. In line with this concept, upstream regulators predicted as activated in monocytes/macrophages from cases of severe fetal inflammatory response compared to a mild response included IL- 6 and IL- $1 \beta$, both of which are cytokines strongly implicated in the intra-amniotic inflammatory response associated with infection [25, 111] (Fig. 5b). Indeed, IL-6 concentrations in the umbilical cord blood are clinically utilized to diagnose fetal inflammatory response syndrome [106, 107, 109]. Upstream regulators predicted as inhibited in monocytes/ macrophages from cases of severe fetal inflammatory response compared to mild response included the anti-inflammatory cytokine IL-10 as well as G protein signaling modulators 1,2, and 3 and Purkinje cell protein 2, which are implicated in chemokine signaling [129-131] (Fig. 5b). The GO biological processes enriched among genes upregulated or downregulated in amniotic fluid monocytes/macrophages were then determined. Among upregulated genes, terms related to cytokine signaling such as "regulation of signaling receptor activity," "cytokine-mediated signaling pathway," "regulation of response to stimulus," "response to external stimulus," and "G protein-coupled receptor signaling pathway" were enriched in monocytes/macrophages from cases of severe fetal inflammatory response compared to those from cas- 


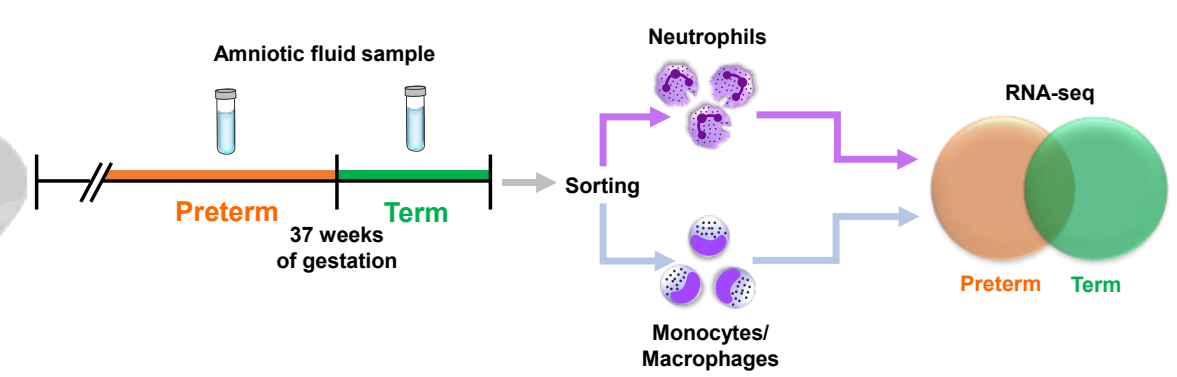

Neutrophils

Preterm vs. Term

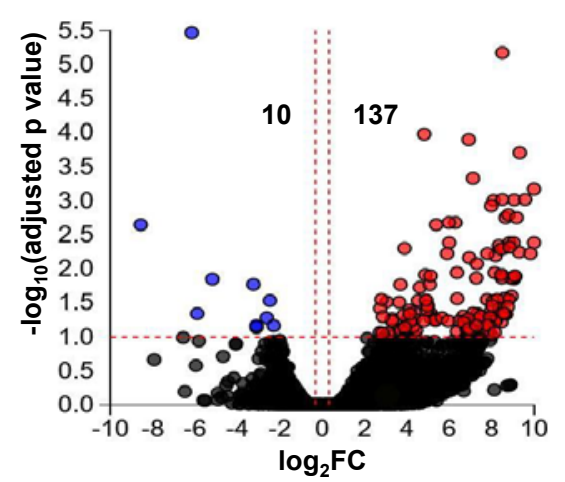

Neutrophils

Biological Pathways

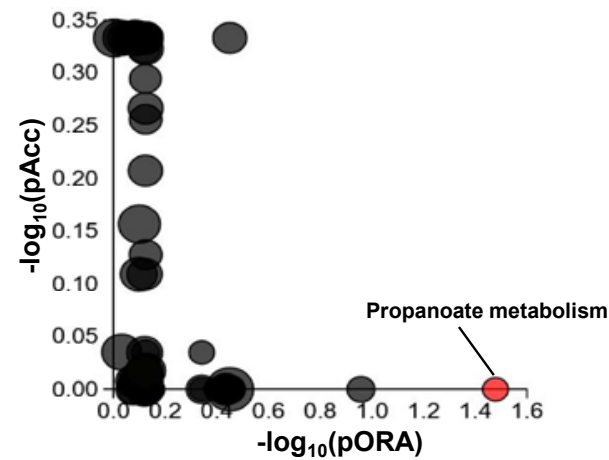

Neutrophils

GO:Biological Processes

Upregulated genes

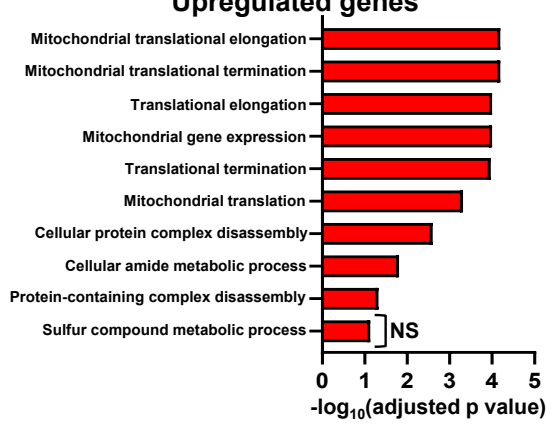

f
Monocytes/
Macrophages

Monocytes/Macrophages

Preterm vs. Term

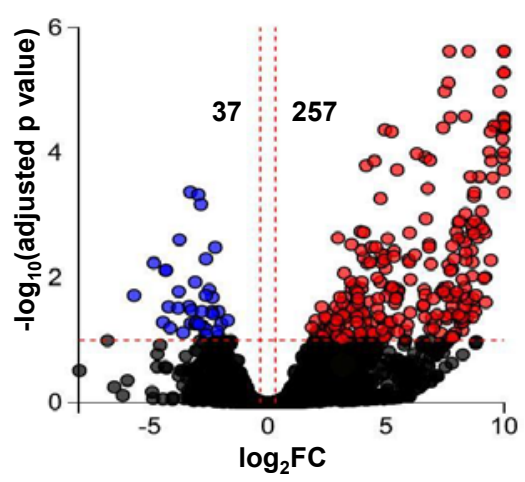

\section{Monocytes/Macrophages}

Biological Pathways

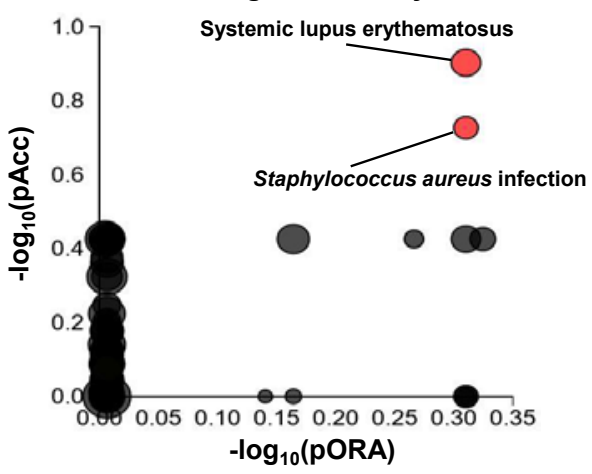

Neutrophils

STRING Analysis

Upregulated Genes

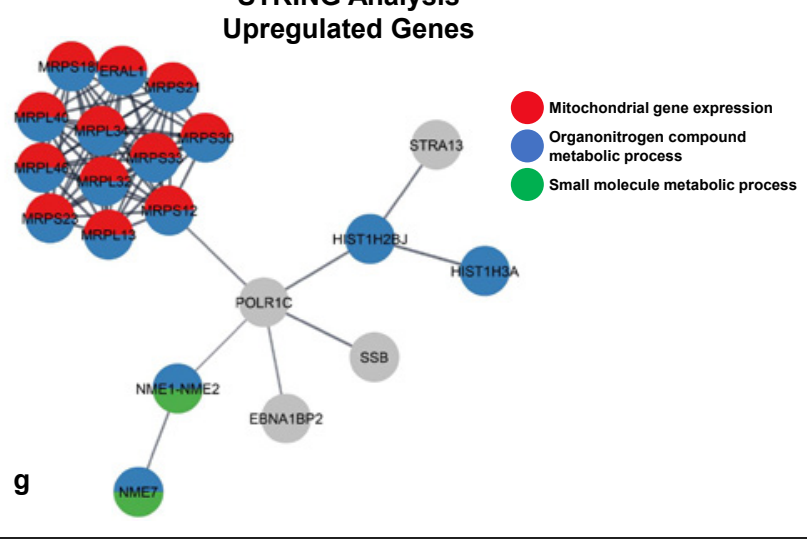

(For legend see next page.) 
es of mild fetal inflammatory response (Fig. 5c). In line with the impacted GO terms, STRING analysis of genes upregulated in monocytes/macrophages from severe fetal inflammatory response showed protein-protein interaction networks related to "cytokine-mediated signaling pathway," "regulation of cell population proliferation," and "extracellular matrix assembly," terms that included multiple innate immune-related chemokines such as CXCL1, CXCL2, and CXCL3 (Fig. 5d). No enriched biological processes were found among genes significantly downregulated in monocytes/macrophages from cases of severe fetal inflammatory response compared to those from cases of mild fetal inflammatory response. Collectively, these findings show that alterations in the transcriptome of amniotic fluid neutrophils and monocytes/ macrophages are strongly associated with the severity of the fetal inflammatory response in the placenta. These data also imply that the trafficking of fetal neutrophils throughout the Wharton's jelly (connective tissue of the human umbilical cord) is modulated by amniotic fluid monocytes/macrophages rather than exclusively by neutrophils, as initially thought [104].

\section{The Transcriptome of Amniotic Fluid Neutrophils}

and Monocytes/Macrophages Based on Pregnancy

Outcome (Preterm or Term Delivery)

Intra-amniotic infection, an established etiology of preterm labor and birth [11, 12, 132-135], is the leading cause of neonatal mortality and morbidity worldwide [136-138]. However, intra-amniotic infection also occurs in term pregnancies [139]. Thus, we finally compared the transcriptomes of amniotic fluid neutrophils and monocytes/macrophages from women who subsequently delivered preterm $(n=4)$ or at term $(n=2)$ (Table 1; Fig. 6a). A total of 147 DEGs were identified in amniotic fluid neutrophils from preterm and term deliveries, with the majority (137 genes) being upregulated and only 10 being

Fig. 6. Transcriptomic differences between amniotic fluid neutrophils and monocytes/macrophages from preterm or term deliveries. a Experimental design demonstrating the transcriptomic comparison of amniotic fluid neutrophils and monocytes/ macrophages between preterm $(n=4)$ and term $(n=2)$ deliveries. b, c Volcano plots showing the differentially expressed genes in amniotic fluid neutrophils (b) and monocytes/macrophages (c) between preterm and term deliveries. d, e pORA and total pAcc showing KEGG pathway impact analysis of amniotic fluid neutrophils (d) and monocytes/macrophages (e) between preterm and term deliveries. Significantly impacted pathways are shown in red. f GO analysis using genes significantly upregulated in amniotic fluid neutrophils from preterm deliveries compared to downregulated (Fig. 6b). Following a similar trend, amniotic fluid monocytes/macrophages from preterm and term deliveries displayed 294 DEGs, with 37 downregulated and 257 upregulated (Fig. 6c). Despite the number of affected genes, only 1 KEGG pathway showed significant enrichment in amniotic fluid neutrophils from preterm and term deliveries: "propanoate metabolism" (Fig. 6d). Similarly, amniotic fluid monocytes/macrophages with differential gene expression between preterm and term deliveries displayed 2 enriched pathways: "S. aureus infection" and "systemic lupus erythematosus," suggesting that some of the identified DEGs were related to inflammatory responses (Fig. 6e). Notably, GO analysis of genes upregulated in amniotic fluid neutrophils from preterm deliveries compared to term deliveries showed enrichment of multiple biological processes associated with mitochondrial translation (Fig. 6f), which were also highly represented in STRING analysis showing upregulated protein-protein interaction networks such as "mitochondrial gene expression" and "organonitrogen compound metabolic process" (Fig. 6g). No biological processes were enriched among genes downregulated in amniotic fluid neutrophils from preterm deliveries compared to those from term deliveries; in addition, amniotic fluid monocytes/macrophages displayed no enriched biological processes among upregulated or downregulated genes for the current comparison. Together, these data show that the amniotic fluid neutrophils and monocytes/macrophages display increased transcriptional activity in preterm deliveries compared to those from term deliveries.

\section{Discussion}

Intra-amniotic infection is a common clinical condition associated with adverse perinatal outcomes [12, 95, $111,140]$. Much research has focused on the mechanisms

those from term deliveries. The top 10 enriched biological processes are shown. g STRING analysis showing a subset of genes upregulated in amniotic fluid neutrophils from preterm deliveries compared to those from term deliveries, represented as nodes in the network. The edges between nodes represent high-confidence protein-protein interactions for the corresponding genes. Red, "Mitochondrial gene expression" network; blue, "organonitrogen compound metabolic process" network; green, "small molecule metabolic process" network; FC, fold change; NS, not significant; pORA, plot based on gene overrepresentation; pAcc, pathway accumulation; GO, Gene Ontology; KEGG, Kyoto Encyclopedia of Genes and Genomes.
RNA-seq of Amniotic Fluid Innate Immune Cells in Intra-Amniotic Infection
J Innate Immun 2021;13:63-82

DOI: $10.1159 / 000509718$ 
triggered by bacteria associated with this clinical condition; however, the host innate immune mechanisms in the intra-amniotic space have been less studied given the invasiveness of amniocentesis (the transabdominal sampling of amniotic fluid). In the current study, we first showed that significant transcriptomic differences exist between amniotic fluid neutrophils and monocytes/macrophages from women with intra-amniotic infection. The plausibility of such differences is supported by significant enrichment results in pathways, biological processes, and predicted upstream regulators between these two innate immune cell types. These findings support our initial hypothesis that neutrophils and monocytes/macrophages serve distinct and important functions in the amniotic cavity of women with intra-amniotic infection.

Neutrophils are classically known for their capacity to phagocytose microbes to prevent the spread of infections, among other roles $[88,141]$. We have shown that neutrophils in the amniotic cavity are fully functional in this regard [92], as they can phagocytose a number of microbes commonly identified in the amniotic fluid of women with intra-amniotic infection such as $U$. urealyticum, $S$. agalactiae, G. vaginalis, and E. coli $[10,12,17,18]$. In line with this concept, KEGG pathways related to phagocytosis or its downstream processes such as "phagosome" and "NOD-like receptor signaling pathway" [142] were enriched in amniotic fluid neutrophils compared to monocytes/macrophages.

Monocytes/macrophages in the amniotic cavity seem to primarily act through the release of pro-inflammatory cytokines that differ from those released by neutrophils $[77,80]$, suggesting that these two cellular subsets have distinct functions in the context of intra-amniotic infection. Accordingly, in the current study, the KEGG pathway analysis showed that multiple terms related to cytokine signaling were significantly enriched when comparing amniotic fluid monocytes/macrophages and neutrophils. Further supporting this concept of amniotic fluid monocytes/macrophages as producers of cytokines/ chemokines, the majority of upstream regulators predicted as more activated in monocytes/macrophages compared to neutrophils were associated with ribosomal proteins (e.g., RPL and RPS family proteins). In addition, GO terms enriched in amniotic fluid monocytes/macrophages were primarily related to ribosomes and protein translation. Collectively, these transcriptomic findings point to amniotic fluid monocytes/macrophages as being highly translationally active, which likely contributes to their release of cytokines/chemokines in the context of intra-amniotic infection.
We and others have shown that amniotic fluid innate immune cells (neutrophils and monocytes/macrophages) can originate from the fetus [82-85] and/or the mother [84-86]. However, until recently, whether fetal and maternal innate immune cells display different functionality in the amniotic cavity has been largely unexplored. In the current study, we found that the transcriptomes of predominantly fetal and maternal neutrophils did not drastically differ, suggesting that these innate immune cells exhibit similar responses against invading microbes regardless of their origin. This finding contrasts with previous reports showing that umbilical cord blood neutrophils display decreased capacity to form NETs $[94,143]$. The differences between fetal neutrophils from umbilical cord blood and those in the amniotic cavity could be explained by the existence of the neonatal NET-inhibitory factor in the umbilical cord blood plasma, which can prevent NET formation [144]. It is therefore tempting to suggest, once fetal neutrophils extravasate from the fetal vasculature into the amniotic cavity [145], that these cells are no longer functionally restricted and can perform similar roles to maternal neutrophils [146].

In contrast with amniotic fluid neutrophils, we observed a significant number of DEGs between predominantly fetal and predominantly maternal amniotic fluid monocytes/macrophages, indicating differences in function between cells from these two origins. Previous studies reported that umbilical cord blood monocytes exhibit reduced expression of cytokines [147] and display impaired capacity for polarization [148]. Thus, it is possible that amniotic fluid monocytes originating from the umbilical cord/chorionic plate [85] may also display reduced capacity for polarization. In line with these observations, predominantly fetal monocytes/macrophages in the amniotic cavity showed downregulation of biological processes, including "cell activation," "immune system processes," and "response to stimuli," despite the pro-inflammatory environment occurring in intra-amniotic infection.

In the current study, RNA-seq revealed that pathways related to inflammation and host immune response were differentially regulated in amniotic fluid monocytes/ macrophages from women with severe fetal inflammatory response compared to those with mild fetal inflammatory response. Pathways related to cytokine signaling, a primary function of monocytes $[149,150]$, were significantly enriched in amniotic fluid monocytes/macrophages from women with severe fetal inflammatory response. These results are in line with previous clinical reports showing that the intra-amniotic inflammatory
76

J Innate Immun 2021;13:63-82 DOI: $10.1159 / 000509718$
Gomez-Lopez et al. 
response induced by bacteria is associated with increased concentrations of pro-inflammatory cytokines in the fetal vasculature of the placenta $[151,152]$. Indeed, neonates born to women with intra-amniotic infection can experience fetal inflammatory response syndrome in utero [95, $97,98]$. This syndrome is characterized by systemic activation of the fetal innate immune system [106, 107, 109], which affects multiple organs and leads to long-term neonatal complications [107, 109].

A notable finding described herein is that the immune cells most affected by the severe fetal inflammatory response of the placenta were amniotic fluid monocytes/ macrophages, which showed significant enrichment of terms related to cytokine/chemokine signaling, including chemokines that drive neutrophil migration $[153,154]$. This is counterintuitive since acute inflammatory processes of the placenta are mainly mediated by neutrophils [104]. Therefore, one would expect that the amniotic fluid neutrophils would display greater transcriptional activity than the monocytes/macrophages in this compartment. Yet, the results presented herein uphold the hypothesis that monocytes/macrophages in the intraamniotic space are central regulators of leukocyte infiltration in the placental tissues.

Our investigation also revealed that both amniotic fluid neutrophils and monocytes/macrophages display greater transcriptional activity in women who delivered preterm than in those who delivered at term. The most logical explanation for this finding, in preterm gestation, is that there is a more hostile intra-amniotic environment than at term; however, both subsets of women displayed an intense inflammatory response in the amniotic cavity as evidenced by elevated IL- 6 concentrations and WBC/viable cell counts. Another possibility is that women who delivered preterm had a greater bacterial burden than those who delivered at term; however, in the current study, molecular microbiology was not performed. Yet, previous studies have established that the intensity of the intra-amniotic inflammatory response is mainly driven by the presence of genital mycoplasmas (Ureaplasma species and Mycoplasma hominis) [155] and, in the current study, both term and preterm intra-amniotic infections were associated with these genital mycoplasmas. An alternative explanation is that women who delivered preterm have amniotic fluid innate immune cells with more activate transcription than those who delivered at term since intra-amniotic inflammation induces fetal lung maturity [156-159], reducing the incidence of respiratory distress syndrome in preterm neonates [160]. This concept supports the hypothesis that intra-amniotic infection/inflammation prepares the fetus for a premature delivery; therefore, preterm labor has survival value for the offspring [161].

In summary, we show that significant transcriptomic differences exist between amniotic fluid neutrophils and monocytes/macrophages from women with intra-amniotic infection that are indicative of the distinct roles these innate immune cells play. We also report that the transcriptome of innate immune cells in the amniotic cavity depends on their fetal or maternal origin. Notably, we demonstrate that the transcriptomic changes in amniotic fluid monocytes/macrophages are associated with the severity of the fetal inflammatory response, suggesting that not only amniotic fluid neutrophils but also monocytes/ macrophages are implicated in the trafficking of fetal leukocytes throughout the umbilical cord (i.e., funisitis). Lastly, we show that amniotic fluid neutrophils and monocytes/macrophages from preterm deliveries display enhanced transcriptional activity compared to those from term deliveries, highlighting the protective role of these innate immune cells in this vulnerable period. Collectively, these findings demonstrate the underlying complexity of local innate immune responses in women with intraamniotic infection and provide new insights into the functions of amniotic fluid neutrophils and monocytes/ macrophages in the amniotic cavity.

\section{Acknowledgements}

We gratefully acknowledge the physicians and nurses from the Center for Advanced Obstetrical Care and Research and the Intrapartum Unit for their help in collecting amniotic fluid samples. The authors also thank the staff members of the PRB Clinical Laboratory and the PRB Histology/Pathology Unit for the processing and examination of the pathological sections.

\section{Statement of Ethics}

Human amniotic fluid samples were obtained at the Perinatology Research Branch, an intramural program of the Eunice Kennedy Shriver National Institute of Child Health and Human Development, National Institutes of Health, U.S. Department of Health and Human Services, Wayne State University (Detroit, MI, USA), and the Detroit Medical Center (Detroit, MI, USA). The collection and use of human materials for research purposes were approved by the Institutional Review Boards of the National Institute of Child Health and Human Development and Wayne State University. All participating women provided written informed consent prior to sample collection.

\section{Conflict of Interest Statement}

The authors have no conflicts of interest to declare.
RNA-seq of Amniotic Fluid Innate Immune Cells in Intra-Amniotic Infection
J Innate Immun 2021;13:63-82

DOI: $10.1159 / 000509718$ 


\section{Funding Sources}

This research was supported by the Perinatology Research Branch, Division of Obstetrics and Maternal-Fetal Medicine, Division of Intramural Research, Eunice Kennedy Shriver National Institute of Child Health and Human Development, National Institutes of Health, U.S. Department of Health and Human Services (NICHD/ $\mathrm{NIH} / \mathrm{DHHS}$ ), and, in part, with federal funds from NICHD/NIH/ DHHS under Contract No. HHSN275201300006C. N. Gomez-Lopez and A.L. Tarca are also supported by the Wayne State University Perinatal Initiative in Maternal, Perinatal, and Child Health. Dr. $\mathrm{R}$. Romero has contributed to this work as part of his official duties as an employee of the United States Federal Government.

\section{Author Contributions}

N. Gomez-Lopez and R. Romero conceived and designed the study. A. Varrey performed the enrollment of patients and collection of samples. Y. Leng and Y. Xu performed experiments. A.L. Tarca, B. Done, G. Bhatti, D. Miller, K. Motomura, M. Gershater, and R. Pique-Regi analyzed data and contributed to data visualization. N. Gomez-Lopez, R. Romero, and A.L. Tarca interpreted the data. All authors wrote the manuscript and approved the final manuscript.

\section{References}

1 Gibbs RS, Romero R, Hillier SL, Eschenbach DA, Sweet RL. A review of premature birth and subclinical infection. Am J Obstet Gynecol. 1992 May;166(5):1515-28.

2 Gomez R, Ghezzi F, Romero R, Muñoz H, Tolosa JE, Rojas I. Premature labor and intraamniotic infection. Clinical aspects and role of the cytokines in diagnosis and pathophysiology. Clin Perinatol. 1995 Jun;22(2):281342.

3 Gonçalves LF, Chaiworapongsa T, Romero R. Intrauterine infection and prematurity. Ment Retard Dev Disabil Res Rev. 2002;8(1):3-13.

4 Keelan JA, Blumenstein M, Helliwell RJ, Sato TA, Marvin KW, Mitchell MD. Cytokines, prostaglandins and parturition: a review. Placenta. 2003 Apr;24(Suppl A):S33-46.

5 Romero R, Espinoza J, Gonçalves LF, Kusanovic JP, Friel L, Hassan S. The role of inflammation and infection in preterm birth. Semin Reprod Med. 2007 Jan;25(1):21-39.

6 Bastek JA, Gómez LM, Elovitz MA. The role of inflammation and infection in preterm birth. Clin Perinatol. 2011 Sep;38(3):385406.

7 Agrawal V, Hirsch E. Intrauterine infection and preterm labor. Semin Fetal Neonatal Med. 2012 Feb;17(1):12-9.

8 Romero R, Gomez-Lopez N, Winters AD, Jung E, Shaman M, Bieda J, et al. Evidence that intra-amniotic infections are often the result of an ascending invasion: a molecular microbiological study. J Perinat Med. 2019 Nov 26;47(9):915-31.

9 Theis KR, Romero R, Motomura K, Galaz J, Winters AD, Pacora P, et al. Microbial burden and inflammasome activation in amniotic fluid of patients with preterm prelabor rupture of membranes. J Perinat Med. 2020 Feb $25 ; 48(2): 115-31$.

10 Gibbs RS, Blanco JD, St Clair PJ, Castaneda YS. Quantitative bacteriology of amniotic fluid from women with clinical intraamniotic infection at term. J Infect Dis. 1982 Jan;145(1): $1-8$.

11 Gravett MG, Hummel D, Eschenbach DA, Holmes KK. Preterm labor associated with subclinical amniotic fluid infection and with bacterial vaginosis. Obstet Gynecol. 1986 Feb; 67(2):229-37.

12 Romero R, Sirtori M, Oyarzun E, Avila C, Mazor M, Callahan R, et al. Infection and labor. V. Prevalence, microbiology, and clinical significance of intraamniotic infection in women with preterm labor and intact membranes. Am J Obstet Gynecol. 1989 Sep; 161(3):817-24.

13 Yoon BH, Chang JW, Romero R. Isolation of Ureaplasma urealyticum from the amniotic cavity and adverse outcome in preterm labor. Obstet Gynecol. 1998 Jul;92(1):77-82.

14 Gravett MG, Adams KM, Sadowsky DW, Grosvenor AR, Witkin SS, Axthelm MK, et al. Immunomodulators plus antibiotics delay preterm delivery after experimental intraamniotic infection in a nonhuman primate model. Am J Obstet Gynecol. 2007 Nov;197(5): 518.e1-8.

15 DiGiulio DB, Romero R, Kusanovic JP, Gómez R, Kim CJ, Seok KS, et al. Prevalence and diversity of microbes in the amniotic fluid, the fetal inflammatory response, and pregnancy outcome in women with preterm pre-labor rupture of membranes. Am J Reprod Immunol. 2010 Jul 1;64(1):38-57.

16 Kallapur SG, Kramer BW, Knox CL, Berry CA, Collins JJ, Kemp MW, et al. Chronic fetal exposure to Ureaplasma parvum suppresses innate immune responses in sheep. J Immunol. 2011 Sep 1;187(5):2688-95.

17 Romero R, Miranda J, Chaiworapongsa T, Chaemsaithong P, Gotsch F, Dong Z, et al. A novel molecular microbiologic technique for the rapid diagnosis of microbial invasion of the amniotic cavity and intra-amniotic infection in preterm labor with intact membranes. Am J Reprod Immunol. 2014 Apr;71(4):330-58.

18 Romero R, Miranda J, Kusanovic JP, Chaiworapongsa $\mathrm{T}$, Chaemsaithong $\mathrm{P}$, Martinez A, et al. Clinical chorioamnionitis at term I: microbiology of the amniotic cavity using cultivation and molecular techniques. J Perinat Med. 2015 Jan;43(1):19-36.

19 Senthamaraikannan P, Presicce P, Rueda CM, Maneenil G, Schmidt AF, Miller LA, et al. Intra-amniotic ureaplasma parvum-induced maternal and fetal inflammation and immune responses in rhesus macaques. J Infect Dis. 2016 Nov 15;214(10):1597-604.

20 Yoon BH, Romero R, Park JY, Oh KJ, Lee J, Conde-Agudelo A, et al. Antibiotic administration can eradicate intra-amniotic infection or intra-amniotic inflammation in a subset of patients with preterm labor and intact membranes. Am J Obstet Gynecol. 2019 Aug; 221(2):142.e1-22.

21 Oh KJ, Romero R, Park JY, Lee J, CondeAgudelo A, Hong J-S, et al. Evidence that antibiotic administration is effective in the treatment of a subset of patients with intra-amniotic infection/inflammation presenting with cervical insufficiency. Am J Obstet Gynecol. 2019 Aug;221(2):140.e1-18.

22 Romero R, Brody DT, Oyarzun E, Mazor M, Wu YK, Hobbins JC, et al. Infection and labor. III. Interleukin-1: a signal for the onset of parturition. Am J Obstet Gynecol. 1989 May; 160(5 Pt 1):1117-23.

23 Romero R, Parvizi ST, Oyarzun E, Mazor M, Wu YK, Avila C, et al. Amniotic fluid interleukin-1 in spontaneous labor at term. J Reprod Med. 1990 Mar;35(3):235-8.

24 Romero R, Ceska M, Avila C, Mazor M, Behnke E, Lindley I. Neutrophil attractant/activating peptide-1/interleukin- 8 in term and preterm parturition. Am J Obstet Gynecol. 1991 Oct;165(4 Pt 1):813-20.

25 Romero R, Mazor M, Brandt F, Sepulveda W, Avila C, Cotton DB, et al. Interleukin-1 alpha and interleukin-1 beta in preterm and term human parturition. Am J Reprod Immunol. 1992 Apr-May;27(3-4):117-23.

26 Esplin MS, Romero R, Chaiworapongsa T, Kim YM, Edwin S, Gomez R, et al. Monocyte chemotactic protein-1 is increased in the amniotic fluid of women who deliver preterm in the presence or absence of intra-amniotic infection. J Matern Fetal Neonatal Med. 2005 Jun;17(6):365-73.

27 Romero R, Grivel JC, Tarca AL, Chaemsaithong $\mathrm{P}, \mathrm{Xu} Z$ Z, Fitzgerald W, et al. Evidence of perturbations of the cytokine network in preterm labor. Am J Obstet Gynecol. 2015 Dec;213(6):836.e1-18. 
28 Kacerovsky M, Musilova I, Stepan M, Andrys C, Drahosova M, Jacobsson B. Detection of intraamniotic inflammation in fresh and processed amniotic fluid samples with the interleukin-6 point of care test. Am J Obstet Gynecol. 2015 Sep;213(3):435-6.

29 Romero R, Chaemsaithong P, Korzeniewski SJ, Tarca AL, Bhatti G, Xu Z, et al. Clinical chorioamnionitis at term II: the intra-amniotic inflammatory response. J Perinat Med. 2016 Jan;44(1):5-22.

30 Bhatti G, Romero R, Rice GE, Fitzgerald W, Pacora P, Gomez-Lopez N, et al. Compartmentalized profiling of amniotic fluid cytokines in women with preterm labor. PLoS One. 2020;15(1):e0227881.

31 Heller KA, Greig PC, Heine RP. Amnioticfluid lactoferrin: a marker for subclinical intraamniotic infection prior to 32 weeks gestation. Infect Dis Obstet Gynecol. 1995;3(5): $179-83$.

32 Otsuki K, Yoda A, Saito H, Mitsuhashi Y, Toma Y, Shimizu Y, et al. Amniotic fluid lactoferrin in intrauterine infection. Placenta. 1999 Mar-Apr;20(2-3):175-9.

33 Pacora P, Maymon E, Gervasi MT, Gomez R, Edwin SS, Yoon BH, et al. Lactoferrin in intrauterine infection, human parturition, and rupture of fetal membranes. Am J Obstet Gynecol. 2000 Oct;183(4):904-10.

34 Espinoza J, Chaiworapongsa T, Romero R, Edwin S, Rathnasabapathy C, Gomez R, et al. Antimicrobial peptides in amniotic fluid: defensins, calprotectin and bacterial/permeability-increasing protein in patients with microbial invasion of the amniotic cavity, intra-amniotic inflammation, preterm labor and premature rupture of membranes. J Matern Fetal Neonatal Med. 2003 Jan;13(1): 2-21.

35 Gravett MG, Novy MJ, Rosenfeld RG, Reddy AP, Jacob T, Turner M, et al. Diagnosis of intra-amniotic infection by proteomic profiling and identification of novel biomarkers. JAMA. 2004 Jul 28;292(4):462-9.

36 Soto E, Espinoza J, Nien JK, Kusanovic JP, Erez O, Richani K, et al. Human beta-defensin-2: a natural antimicrobial peptide present in amniotic fluid participates in the host response to microbial invasion of the amniotic cavity. J Matern Fetal Neonatal Med. 2007 Jan;20(1):15-22.

37 Varrey A, Romero R, Panaitescu B, Miller D, Chaiworapongsa T, Patwardhan $\mathrm{M}$, et al. $\mathrm{Hu}$ man $\beta$-defensin-1: a natural antimicrobial peptide present in amniotic fluid that is increased in spontaneous preterm labor with intra-amniotic infection. Am J Reprod Immunol. 2018 Oct;80(4):e13031.

38 Para R, Romero R, Miller D, Panaitescu B, Varrey A, Chaiworapongsa T, et al. Human $\beta$-defensin-3 participates in intra-amniotic host defense in women with labor at term, spontaneous preterm labor and intact membranes, and preterm prelabor rupture of membranes. J Matern Fetal Neonatal Med. 2019 Apr 18:1-16.
39 Romero R, Emamian M, Quintero R, Wan M, Hobbins JC, Mitchell MD. Amniotic fluid prostaglandin levels and intra-amniotic infections. Lancet. 1986 Jun 14;1(8494):1380.

40 Romero R, Emamian M, Wan M, Quintero R, Hobbins JC, Mitchell MD. Prostaglandin concentrations in amniotic fluid of women with intra-amniotic infection and preterm labor. Am J Obstet Gynecol. 1987 Dec;157(6): 1461-7.

41 Romero R, Wu YK, Mazor M, Hobbins JC, Mitchell MD. Amniotic fluid prostaglandin E2 in preterm labor. Prostaglandins Leukot Essent Fatty Acids. 1988 Dec;34(3):141-5.

42 Bry K, Hallman M. Prostaglandins, inflammation, and preterm labor. J Perinatol. 1989 Mar;9(1):60-5.

43 Romero R, Wu YK, Mazor M, Oyarzun E, Hobbins JC, Mitchell MD. Amniotic fluid arachidonate lipoxygenase metabolites in preterm labor. Prostaglandins Leukot Essent Fatty Acids. 1989 May;36(2):69-75.

44 Mazor M, Wiznitzer A, Maymon E, Leiberman JR, Cohen A. Changes in amniotic fluid concentrations of prostaglandins E2 and F2 alpha in women with preterm labor. Isr J Med Sci. 1990 Aug;26(8):425-8.

45 Hsu CD, Meaddough E, Aversa K, Hong SF, Lee IS, Bahodo-Singh RO, et al. Dual roles of amniotic fluid nitric oxide and prostaglandin E2 in preterm labor with intra-amniotic infection. Am J Perinatol. 1998;15(12):683-7.

46 Lee SE, Park IS, Romero R, Yoon BH. Amniotic fluid prostaglandin F2 increases even in sterile amniotic fluid and is an independent predictor of impending delivery in preterm premature rupture of membranes. J Matern Fetal Neonatal Med. 2009 Oct;22(10):880-6.

47 Maddipati KR, Romero R, Chaiworapongsa T, Zhou SL, Xu Z, Tarca AL, et al. Eicosanomic profiling reveals dominance of the epoxygenase pathway in human amniotic fluid at term in spontaneous labor. FASEB J. 2014 Nov;28(11):4835-46.

48 Park JY, Ahn TG, Lee J, Yoon BH. 737: Elevated prostaglandin F2a concentration in amniotic fluid is an independent risk factor for intra-amniotic inflammation and adverse pregnancy outcome in patients with preterm labor. Am J Obstet Gynecol. 2015 Jan;212(1):S360.

49 Park JY, Romero R, Lee J, Chaemsaithong P, Chaiyasit N, Yoon BH. An elevated amniotic fluid prostaglandin F2 $\alpha$ concentration is associated with intra-amniotic inflammation/ infection, and clinical and histologic chorioamnionitis, as well as impending preterm delivery in patients with preterm labor and intact membranes. J Matern Fetal Neonatal Med. 2016 Aug;29(16):2563-72.

50 Maddipati KR, Romero R, Chaiworapongsa T, Chaemsaithong P, Zhou SL, Xu Z, et al. Clinical chorioamnionitis at term: the amniotic fluid fatty acyl lipidome. J Lipid Res. 2016 Oct;57(10):1906-16.

51 Maddipati KR, Romero R, Chaiworapongsa T, Chaemsaithong P, Zhou SL, Xu Z, et al. Lipidomic analysis of patients with microbial invasion of the amniotic cavity reveals upregulation of leukotriene B4. FASEB J. 2016 Oct;30(10):3296-307.

52 Peiris HN, Romero R, Vaswani K, Reed S, Gomez-Lopez N, Tarca AL, et al. Preterm labor is characterized by a high abundance of amniotic fluid prostaglandins in patients with intra-amniotic infection or sterile intra-amniotic inflammation. J Matern Fetal Neonatal Med. 2019 Dec 29:1-16.

53 Gibbs RS, Dinsmoor MJ, Newton ER, Ramamurthy RS. A randomized trial of intrapartum versus immediate postpartum treatment of women with intra-amniotic infection. Obstet Gynecol. 1988 Dec;72(6):823-8.

54 Gilstrap LC 3rd, Cox SM. Acute chorioamnionitis. Obstet Gynecol Clin North Am. 1989 Jun;16(2):373-9.

55 Gibbs RS, Duff P. Progress in pathogenesis and management of clinical intraamniotic infection. Am J Obstet Gynecol. 1991 May; 164(5 Pt 1):1317-26.

56 Newton ER. Chorioamnionitis and intraamniotic infection. Clin Obstet Gynecol. 1993 Dec;36(4):795-808.

57 Rouse DJ, Landon M, Leveno KJ, Leindecker S, Varner MW, Caritis SN, et al. The maternal-fetal medicine units cesarean registry: chorioamnionitis at term and its duration-relationship to outcomes. Am J Obstet Gynecol. 2004 Jul;191(1):211-6.

58 Tita AT, Andrews WW. Diagnosis and management of clinical chorioamnionitis. Clin Perinatol. 2010 Jun;37(2):339-54.

59 Romero R, Chaemsaithong P, Docheva N, Korzeniewski SJ, Tarca AL, Bhatti G, et al. Clinical chorioamnionitis at term IV: the maternal plasma cytokine profile. J Perinat Med. 2016 Jan;44(1):77-98.

60 Oleen MA, Mariano JP. Controlling refractory atonic postpartum hemorrhage with Hemabate sterile solution. Am J Obstet Gynecol. 1990 Jan;162(1):205-8.

61 Tran TS, Jamulitrat S, Chongsuvivatwong V, Geater A. Risk factors for postcesarean surgical site infection. Obstet Gynecol. 2000 Mar; 95(3):367-71.

62 Yoon BH, Jun JK, Romero R, Park KH, Gomez $\mathrm{R}$, Choi JH, et al. Amniotic fluid inflammatory cytokines (interleukin-6, interleukin-1beta, and tumor necrosis factor-alpha), neonatal brain white matter lesions, and cerebral palsy. Am J Obstet Gynecol. 1997 Jul;177(1):19-26.

63 Yoon BH, Romero R, Jun JK, Park KH, Park JD, Ghezzi F, et al. Amniotic fluid cytokines (interleukin-6, tumor necrosis factor-alpha, interleukin-1 beta, and interleukin-8) and the risk for the development of bronchopulmonary dysplasia. Am J Obstet Gynecol. 1997 Oct:177(4):825-30.

64 Alexander JM, McIntire DM, Leveno KJ. Chorioamnionitis and the prognosis for term infants. Obstet Gynecol. 1999 Aug;94(2):274-8.

65 De Felice C C, Toti P, Laurini RN, Stumpo M, Picciolini E, Todros T, et al. Early neonatal brain injury in histologic chorioamnionitis. J Pediatr. 2001 Jan;138(1):101-4.
RNA-seq of Amniotic Fluid Innate Immune Cells in Intra-Amniotic Infection
J Innate Immun 2021;13:63-82 DOI: $10.1159 / 000509718$ 
66 Willoughby RE Jr, Nelson KB. Chorioamnionitis and brain injury. Clin Perinatol. 2002 Dec;29(4):603-21.

$67 \mathrm{Wu}$ YW, Escobar GJ, Grether JK, Croen LA, Greene JD, Newman TB. Chorioamnionitis and cerebral palsy in term and near-term infants. JAMA. 2003 Nov 26;290(20):2677-84.

68 Oh KJ, Park JY, Lee J, Hong JS, Romero R, Yoon $\mathrm{BH}$. The combined exposure to intraamniotic inflammation and neonatal respiratory distress syndrome increases the risk of intraventricular hemorrhage in preterm neonates. J Perinat Med. 2018 Jan 26;46(1):9-20.

69 Randis TM, Rice MM, Myatt L, Tita ATN, Leveno KJ, Reddy UM, et al. Incidence of early-onset sepsis in infants born to women with clinical chorioamnionitis. J Perinat Med. 2018 Oct 25;46(8):926-33.

70 Visconti K, Senthamaraikannan P, Kemp MW, Saito M, Kramer BW, Newnham JP, et al. Extremely preterm fetal sheep lung responses to antenatal steroids and inflammation. Am J Obstet Gynecol. 2018 Mar;218(3): 349.e1-10.

71 Gravett MG. Successful treatment of intraamniotic infection/inflammation: a paradigm shift. Am J Obstet Gynecol. 2019 Aug;221(2): 83-5.

72 Romero R, Quintero R, Nores J, Avila C, Mazor M, Hanaoka S, et al. Amniotic fluid white blood cell count: a rapid and simple test to diagnose microbial invasion of the amniotic cavity and predict preterm delivery. Am J Obstet Gynecol. 1991 Oct;165(4 Pt 1):821-30.

73 Romero R, Yoon BH, Mazor M, Gomez R, Diamond MP, Kenney JS, et al. The diagnostic and prognostic value of amniotic fluid white blood cell count, glucose, interleukin-6, and gram stain in patients with preterm labor and intact membranes. Am J Obstet Gynecol. 1993 Oct;169(4):805-16.

74 Romero R, Yoon BH, Mazor M, Gomez R, Gonzalez R, Diamond MP, et al. A comparative study of the diagnostic performance of amniotic fluid glucose, white blood cell count, interleukin-6, and gram stain in the detection of microbial invasion in patients with preterm premature rupture of membranes. Am J Obstet Gynecol. 1993 Oct;169(4):839-51.

75 Gomez R, Romero R, Galasso M, Behnke E, Insunza $\mathrm{A}$, Cotton DB. The value of amniotic fluid interleukin-6, white blood cell count, and gram stain in the diagnosis of microbial invasion of the amniotic cavity in patients at term. Am J Reprod Immunol. 1994 Oct;32(3): 200-10.

76 Yoon BH, Yang SH, Jun JK, Park KH, Kim CJ, Romero R. Maternal blood C-reactive protein, white blood cell count, and temperature in preterm labor: a comparison with amniotic fluid white blood cell count. Obstet Gynecol. 1996 Feb;87(2):231-7.

77 Martinez-Varea A, Romero R, Xu Y, Miller D, Ahmed AI, Chaemsaithong P, et al. Clinical chorioamnionitis at term VII: the amniotic fluid cellular immune response. J Perinat Med. 2017;45(5):523-38.
78 Gomez-Lopez N, Romero R, Xu Y, Miller D, Leng Y, Panaitescu B, et al. The immunophenotype of amniotic fluid leukocytes in normal and complicated pregnancies. Am J Reprod Immunol. 2018 Apr;79(4):e12827.

79 Gomez-Lopez N, Romero R, Galaz J, Xu Y, Panaitescu B, Slutsky R, et al. Cellular immune responses in amniotic fluid of women with preterm labor and intra-amniotic infection or intra-amniotic inflammation. Am J Reprod Immunol. 2019 Nov;82(5):e13171.

80 Galaz J, Romero R, Xu Y, Miller D, Slutsky R, Levenson $\mathrm{D}$, et al. Cellular immune responses in amniotic fluid of women with preterm clinical chorioamnionitis. Inflamm Res. 2020 Feb;69(2):203-16.

81 Galaz J, Romero R, Slutsky R, Xu Y, Motomura K, Para R, et al. Cellular immune responses in amniotic fluid of women with preterm prelabor rupture of membranes. J Perinat Med. 2020 Mar 26;48(3):222-33.

82 Sampson JE, Theve RP, Blatman RN, Shipp TD, Bianchi DW, Ward BE, et al. Fetal origin of amniotic fluid polymorphonuclear leukocytes. Am J Obstet Gynecol. 1997 Jan;176(1 Pt 1):77-81.

83 Macias AE, Wong SW, Sadowsky DW, Luetjens CM, Axthelm MK, Gravett MG, et al. Maternal or fetal origin of rhesus monkey (Macaca mulatta) amniotic fluid leukocytes can be identified by polymerase chain reaction using the zinc finger Y gene. Am J Primatol. 2001 Nov;55(3):159-70.

84 Gomez-Lopez N, Romero R, Xu Y, Leng Y, Garcia-Flores V, Miller D, et al. Are amniotic fluid neutrophils in women with intraamniotic infection and/or inflammation of fetal or maternal origin? Am J Obstet Gynecol. 2017 Dec;217(6):693.e1-16.

85 Gomez-Lopez N, Romero R, Leng Y, Xu Y, Slutsky R, Levenson D, et al. The origin of amniotic fluid monocytes/macrophages in women with intra-amniotic inflammation or infection. J Perinat Med. 2019 Oct 25;47(8): $822-40$.

86 Blanc WA. Pathology of the placenta and cord in ascending and in haematogenous infection. Ciba Found Symp. 1979;(77):17-38.

87 Kaplan MJ, Radic M. Neutrophil extracellular traps: double-edged swords of innate immunity. J Immunol. 2012 Sep 15;189(6):2689-95.

88 Mayadas TN, Cullere X, Lowell CA. The multifaceted functions of neutrophils. Annu Rev Pathol. 2014;9:181-218.

89 Kobayashi SD, Malachowa N, DeLeo FR. Neutrophils and bacterial immune evasion. J Innate Immun. 2018;10(5-6):432-41.

90 Dahlgren C, Karlsson A, Bylund J. Intracellular neutrophil oxidants: from laboratory curiosity to clinical reality. J Immunol. 2019 Jun 1;202(11):3127-34

91 Francis A, Bosio E, Stone SF, Fatovich DM, Arendts G, MacDonald SPJ, et al. Markers involved in innate immunity and neutrophil activation are elevated during acute human anaphylaxis: validation of a microarray study. J Innate Immun. 2019;11(1):63-73.
92 Gomez-Lopez N, Romero R, Garcia-Flores $\mathrm{V}, \mathrm{Xu} \mathrm{Y}$, Leng Y, Alhousseini A, et al. Amniotic fluid neutrophils can phagocytize bacteria: a mechanism for microbial killing in the amniotic cavity. Am J Reprod Immunol. 2017 Oct;78(4)

93 Maymon E, Romero R, Chaiworapongsa T, Kim JC, Berman S, Gomez R, et al. Value of amniotic fluid neutrophil collagenase concentrations in preterm premature rupture of membranes. Am J Obstet Gynecol. 2001 Nov; 185(5):1143-8.

94 Gomez-Lopez N, Romero R, Xu Y, Miller D, Unkel R, Shaman M, et al. Neutrophil extracellular traps in the amniotic cavity of women with intra-amniotic infection: a new mechanism of host defense. Reprod Sci. 2017 Aug;24(8):1139-53.

95 Romero R, Mazor M. Infection and preterm labor. Clin Obstet Gynecol. 1988 Sep;31(3): 553-84.

96 Kramer BW, Moss TJ, Willet KE, Newnham JP, Sly PD, Kallapur SG, et al. Dose and time response after intraamniotic endotoxin in preterm lambs. Am J Respir Crit Care Med. 2001 Sep 15;164(6):982-8.

97 Chaiworapongsa T, Romero R, Kim JC, Kim YM, Blackwell SC, Yoon BH, et al. Evidence for fetal involvement in the pathologic process of clinical chorioamnionitis. Am J Obstet Gynecol. 2002 Jun;186(6):1178-82.

98 Witt A, Berger A, Gruber CJ, Petricevic L, Apfalter P, Husslein P. IL-8 concentrations in maternal serum, amniotic fluid and cord blood in relation to different pathogens within the amniotic cavity. J Perinat Med. 2005;33(1):22-6.

99 Kallapur SG, Nitsos I, Moss TJ, Polglase GR Pillow JJ, Cheah FC, et al. IL-1 mediates pulmonary and systemic inflammatory responses to chorioamnionitis induced by lipopolysaccharide. Am J Respir Crit Care Med. 2009 May 15;179(10):955-61.

100 Kemp MW, Kannan PS, Saito M, Newnham JP, Cox T, Jobe AH, et al. Selective exposure of the fetal lung and skin/amnion (but not gastro-intestinal tract) to LPS elicits acute systemic inflammation in fetal sheep. PLoS One. 2013;8(5):e63355.

101 Mitchell T, MacDonald JW, Srinouanpranchanh S, Bammler TK, Merillat S, Boldenow $\mathrm{E}$, et al. Evidence of cardiac involvement in the fetal inflammatory response syndrome: disruption of gene networks programming cardiac development in nonhuman primates. Am J Obstet Gynecol. 2018 Apr; 218(4):438.e1-16.

102 Garcia-Flores V, Romero R, Miller D, Xu Y, Done B, Veerapaneni C, et al. Inflammationinduced adverse pregnancy and neonatal outcomes can be improved by the immunomodulatory peptide exendin-4. Front Immunol. 2018;9:1291. 
103 Pacora $\mathrm{P}$, Chaiworapongsa T, Maymon E, Kim YM, Gomez R, Yoon BH, et al. Funisitis and chorionic vasculitis: the histological counterpart of the fetal inflammatory response syndrome. J Matern Fetal Neonatal Med. 2002 Jan;11(1):18-25.

104 Kim CJ, Romero R, Chaemsaithong P, Chaiyasit N, Yoon BH, Kim YM. Acute chorioamnionitis and funisitis: definition, pathologic features, and clinical significance. Am J Obstet Gynecol. 2015 Oct;213(4 Suppl 1): S29-52.

105 Redline RW. Classification of placental lesions. Am J Obstet Gynecol. 2015 Oct;213(4 Suppl 1):S21-8.

106 Romero R, Gomez R, Ghezzi F, Yoon BH, Mazor M, Edwin SS, et al. A fetal systemic inflammatory response is followed by the spontaneous onset of preterm parturition. Am J Obstet Gynecol. 1998 Jul;179(1):18693.

107 Gomez R, Romero R, Ghezzi F, Yoon BH, Mazor M, Berry SM. The fetal inflammatory response syndrome. Am J Obstet Gynecol. 1998 Jul;179(1):194-202.

108 Yoon BH, Romero R, Kim KS, Park JS, Ki $\mathrm{SH}$, Kim BI, et al. A systemic fetal inflammatory response and the development of bronchopulmonary dysplasia. Am J Obstet Gynecol. 1999 Oct;181(4):773-9.

109 Gotsch F, Romero R, Kusanovic JP, MazakiTovi S, Pineles BL, Erez O, et al. The fetal inflammatory response syndrome. Clin Obstet Gynecol. 2007 Sep;50(3):652-83.

110 Mestan K, Yu Y, Thorsen P, Skogstrand K, Matoba N, Liu X, et al. Cord blood biomarkers of the fetal inflammatory response. J Matern Fetal Neonatal Med. 2009 May;22(5): 379-87.

111 Yoon BH, Romero R, Moon JB, Shim SS, Kim M, Kim G, et al. Clinical significance of intraamniotic inflammation in patients with preterm labor and intact membranes. Am J Obstet Gynecol. 2001 Nov;185(5):1130-6.

112 Romero R, Chaemsaithong P, Chaiyasit N, Docheva N, Dong Z, Kim CJ, et al. CXCL10 and IL-6: markers of two different forms of intra-amniotic inflammation in preterm labor. Am J Reprod Immunol. 2017 Jul;78(1).

113 Romero R, Miranda J, Chaiworapongsa T, Korzeniewski SJ, Chaemsaithong P, Gotsch $\mathrm{F}$, et al. Prevalence and clinical significance of sterile intra-amniotic inflammation in patients with preterm labor and intact membranes. Am J Reprod Immunol. 2014 Nov; 72(5):458-74.

114 Gomez-Lopez N, Romero R, Panaitescu B, Leng Y, Xu Y, Tarca AL, et al. Inflammasome activation during spontaneous preterm labor with intra-amniotic infection or sterile intra-amniotic inflammation. Am J Reprod Immunol. 2018 Nov;80(5):e13049.

115 Romero R, Emamian M, Quintero R, Wan M, Hobbins JC, Mazor M, et al. The value and limitations of the Gram stain examination in the diagnosis of intraamniotic infection. Am J Obstet Gynecol. 1988 Jul;159(1):114-9.
116 Romero R, Jimenez C, Lohda AK, Nores J, Hanaoka S, Avila C, et al. Amniotic fluid glucose concentration: a rapid and simple method for the detection of intraamniotic infection in preterm labor. Am J Obstet Gynecol. 1990 Sep;163(3):968-74.

117 Kim MJ, Romero R, Gervasi MT, Kim JS, Yoo W, Lee DC, et al. Widespread microbial invasion of the chorioamniotic membranes is a consequence and not a cause of intraamniotic infection. Lab Invest. 2009 Aug; 89(8):924-36.

118 Patro R, Duggal G, Love MI, Irizarry RA, Kingsford C. Salmon provides fast and biasaware quantification of transcript expression. Nat Methods. 2017 Apr;14(4):417-9.

119 Love MI, Huber W, Anders S. Moderated estimation of fold change and dispersion for RNA-seq data with DESeq2. Genome Biol. 2014;15(12):550.

120 Gentleman RC, Carey VJ, Bates DM, Bolstad B, Dettling M, Dudoit S, et al. Bioconductor: open software development for computational biology and bioinformatics. Genome Biol. 2004;5(10):R80.

121 Draghici S, Khatri P, Tarca AL, Amin K, Done A, Voichita C, et al. A systems biology approach for pathway level analysis. Genome Res. 2007 Oct;17(10):1537-45.

122 Tarca AL, Draghici S, Khatri P, Hassan SS, Mittal P, Kim JS, et al. A novel signaling pathway impact analysis. Bioinformatics. 2009 Jan 1;25(1):75-82.

123 Khatri P, Draghici S, Tarca AL, Hassan SS, Romero R. A system biology approach for the steady-state analysis of gene signaling networks. In: Rueda L, Mery D, Kittler J, editors. Lecture notes in computer science. Berlin: Springer; 2007. 4756.

124 Kanehisa M, Goto S. KEGG: kyoto encyclopedia of genes and genomes. Nucleic Acids Res. 2000 Jan 1;28(1):27-30.

125 Kanehisa M, Goto S, Sato Y, Furumichi M, Tanabe M. KEGG for integration and interpretation of large-scale molecular data sets. Nucleic Acids Res. 2012 Jan;40(Database issue):D109-14.

126 Doncheva NT, Morris JH, Gorodkin J, Jensen LJ. Cytoscape stringapp: network analysis and visualization of proteomics data. J Proteome Res. 2019 Feb 1;18(2):623-32.

127 Otasek D, Morris JH, Bouças J, Pico AR, Demchak B. Cytoscape automation: empowering workflow-based network analysis. Genome Biol. 2019 Sep 2;20(1):185.

128 Ashburner M, Ball CA, Blake JA, Botstein D, Butler H, Cherry JM, et al. Gene ontology: tool for the unification of biology. The Gene Ontology Consortium. Nat Genet. 2000 May;25(1):25-9.

129 Giguère PM, Billard MJ, Laroche G, Buckley BK, Timoshchenko RG, McGinnis MW, et al. G-protein signaling modulator-3, a gene linked to autoimmune diseases, regulates monocyte function and its deficiency protects from inflammatory arthritis. Mol Immunol. 2013 Jun;54(2):193-8.
130 Branham-O'Connor M, Robichaux WG 3rd Zhang XK, Cho H, Kehrl JH, Lanier SM, et al. Defective chemokine signal integration in leukocytes lacking activator of $\mathrm{G}$ protein signaling 3 (AGS3). J Biol Chem. 2014 Apr 11; 289(15):10738-47.

131 Billard MJ, Gall BJ, Richards KL, Siderovski DP, Tarrant TK. G protein signaling modulator-3: a leukocyte regulator of inflammation in health and disease. Am J Clin Exp Immunol. 2014;3(2):97-106.

132 Gravett MG, Witkin SS, Haluska GJ, Edwards JL, Cook MJ, Novy MJ. An experimental model for intraamniotic infection and preterm labor in rhesus monkeys. Am J Obstet Gynecol. 1994 Dec;171(6):1660-7.

133 Romero R, Dey SK, Fisher SJ. Preterm labor: one syndrome, many causes. Science. 2014 Aug 15;345(6198):760-5.

134 Combs CA, Gravett M, Garite TJ, Hickok DE, Lapidus J, Porreco R, et al. Amniotic fluid infection, inflammation, and colonization in preterm labor with intact membranes. Am J Obstet Gynecol. 2014 Feb;210(2):125. e1-15.

135 Strauss JF 3rd, Romero R, Gomez-Lopez N, Haymond-Thornburg H, Modi BP, Teves $\mathrm{ME}$, et al. Spontaneous preterm birth: advances toward the discovery of genetic predisposition. Am J Obstet Gynecol. 2018 Mar; 218(3):294-314.e2.

136 Blencowe H, Cousens S, Oestergaard MZ, Chou D, Moller AB, Narwal R, et al. National, regional, and worldwide estimates of preterm birth rates in the year 2010 with time trends since 1990 for selected countries: a systematic analysis and implications. Lancet. 2012 Jun 9;379(9832):2162-72.

137 Manuck TA, Rice MM, Bailit JL, Grobman WA, Reddy UM, Wapner RJ, et al. Preterm neonatal morbidity and mortality by gestational age: a contemporary cohort. Am J Obstet Gynecol. 2016 Jul;215(1):103.e1-14.

138 Chawanpaiboon S, Vogel JP, Moller AB, Lumbiganon P, Petzold M, Hogan D, et al. Global, regional, and national estimates of levels of preterm birth in 2014: a systematic review and modelling analysis. Lancet Glob Health. 2019 Jan;7(1):e37-46.

139 Romero R, Chaemsaithong P, Docheva N, Korzeniewski SJ, Kusanovic JP, Yoon BH, et al. Clinical chorioamnionitis at term VI: acute chorioamnionitis and funisitis according to the presence or absence of microorganisms and inflammation in the amniotic cavity. J Perinat Med. 2016 Jan;44(1): 33-51.

140 Cobo T, Vives I, Rodríguez-Trujillo A, Murillo C, Ángeles MA, Bosch J, et al. Impact of microbial invasion of amniotic cavity and the type of microorganisms on short-term neonatal outcome in women with preterm labor and intact membranes. Acta Obstet Gynecol Scand. 2017 May;96(5):570-9.

141 Nordenfelt P, Tapper H. Phagosome dynamics during phagocytosis by neutrophils. J Leukoc Biol. 2011 Aug;90(2):271-84.
RNA-seq of Amniotic Fluid Innate Immune Cells in Intra-Amniotic Infection
J Innate Immun 2021;13:63-82 DOI: $10.1159 / 000509718$ 
142 Franchi L, Warner N, Viani K, Nuñez G. Function of Nod-like receptors in microbial recognition and host defense. Immunol Rev. 2009 Jan;227(1):106-28.

143 Boldenow E, Gendrin C, Ngo L, Bierle C, Vornhagen J, Coleman M, et al. Group B Streptococcus circumvents neutrophils and neutrophil extracellular traps during amniotic cavity invasion and preterm labor. Sci Immunol. 2016 Oct;1(4):eaah4576.

144 Yost CC, Schwertz H, Cody MJ, Wallace JA, Campbell RA, Vieira-de-Abreu A, et al. Neonatal NET-inhibitory factor and related peptides inhibit neutrophil extracellular trap formation. J Clin Invest. 2016 Oct 3;126(10): 3783-98.

145 Lee SD, Kim MR, Hwang PG, Shim SS, Yoon $\mathrm{BH}$, Kim CJ. Chorionic plate vessels as an origin of amniotic fluid neutrophils. Pathol Int. 2004 Jul;54(7):516-22.

146 Fong ON, Chan KY, Leung KT, Lam HS, Cheung HM, Leung TY, et al. Expression profile of cord blood neutrophils and dysregulation of HSPA1A and OLR1 upon challenge by bacterial peptidoglycan. J Leukoc Biol. 2014 Jan;95(1):169-78.

147 Dreschers S, Ohl K, Lehrke M, Möllmann J, Denecke B, Costa I, et al. Impaired cellular energy metabolism in cord blood macrophages contributes to abortive response toward inflammatory threats. Nat Commun. 2019 Apr 11;10(1):1685.

148 Dreschers S, Ohl K, Schulte N, Tenbrock K, Orlikowsky TW. Impaired functional capacity of polarised neonatal macrophages. Sci Rep. 2020 Jan 17;10(1):624.
149 Gordon S, Taylor PR. Monocyte and macrophage heterogeneity. Nat Rev Immunol. 2005 Dec;5(12):953-64.

150 Serbina NV, Jia T, Hohl TM, Pamer EG. Monocyte-mediated defense against microbial pathogens. Annu Rev Immunol. 2008; 26:421-52.

151 Yoon BH, Romero R, Park JS, Kim M, Oh SY, Kim CJ, et al. The relationship among inflammatory lesions of the umbilical cord (funisitis), umbilical cord plasma interleukin 6 concentration, amniotic fluid infection, and neonatal sepsis. Am J Obstet Gynecol. 2000 Nov; 183(5):1124-9.

152 Park CW, Moon KC, Park JS, Jun JK, Romero R, Yoon BH. The involvement of human amnion in histologic chorioamnionitis is an indicator that a fetal and an intra-amniotic inflammatory response is more likely and severe: clinical implications. Placenta. 2009 Jan;30(1):56-61.

153 Sawant KV, Poluri KM, Dutta AK, Sepuru KM, Troshkina A, Garofalo RP, et al. Chemokine CXCL1 mediated neutrophil recruitment: role of glycosaminoglycan interactions. Sci Rep. 2016 Sep 14;6:33123.

154 Rajarathnam K, Schnoor M, Richardson RM, Rajagopal S. How do chemokines navigate neutrophils to the target site: dissecting the structural mechanisms and signaling pathways. Cell Signal. 2019 Feb;54:69-80.

155 Oh KJ, Lee KA, Sohn YK, Park CW, Hong JS, Romero R, et al. Intraamniotic infection with genital mycoplasmas exhibits a more intense inflammatory response than intraamniotic infection with other microorganisms in patients with preterm premature rupture of membranes. Am J Obstet Gynecol. 2010 Sep;203(3):211.e1-8.
156 Jobe AH, Newnham JP, Willet KE, Moss TJ, Gore Ervin M, Padbury JF, et al. Endotoxininduced lung maturation in preterm lambs is not mediated by cortisol. Am J Respir Crit Care Med. 2000 Nov;162(5):1656-61.

157 Kallapur SG, Willet KE, Jobe AH, Ikegami $\mathrm{M}$, Bachurski CJ. Intra-amniotic endotoxin: chorioamnionitis precedes lung maturation in preterm lambs. Am J Physiol Lung Cell Mol Physiol. 2001 Mar;280(3):L527-36.

158 Kramer BW, Kramer S, Ikegami M, Jobe $\mathrm{AH}$. Injury, inflammation, and remodeling in fetal sheep lung after intra-amniotic endotoxin. Am J Physiol Lung Cell Mol Physiol. 2002 Aug;283(2):L452-9.

159 Moss TJ, Nitsos I, Kramer BW, Ikegami M, Newnham JP, Jobe AH. Intra-amniotic endotoxin induces lung maturation by direct effects on the developing respiratory tract in preterm sheep. Am J Obstet Gynecol. 2002 Oct:187(4):1059-65.

160 Shimoya K, Taniguchi T, Matsuzaki N, Moriyama A, Murata Y, Kitajima H, et al. Chorioamnionitis decreased incidence of respiratory distress syndrome by elevating fetal interleukin-6 serum concentration. Hum Reprod. 2000 Oct;15(10):2234-40.

161 Lee J, Seong HS, Kim BJ, Jun JK, Romero R, Yoon BH. Evidence to support that spontaneous preterm labor is adaptive in nature: neonatal RDS is more common in "indicated" than in "spontaneous" preterm birth. Perinat Med. 2009;37(1):53-8. 